\title{
Neuroactive venom compounds obtained from Phlogiellus bundokalbo as potential leads for neurodegenerative diseases: insights on their acetylcholinesterase and beta-secretase inhibitory activities in vitro
}

\author{
Simon Miguel M. Lopez ${ }^{1,4}$ (D), Jeremey S. Aguilar ${ }^{1}$, Jerene Bashia B. Fernandez ${ }^{1}$, Angelic Gayle J. Lao ${ }^{1}$, \\ Mitzi Rain R. Estrella ${ }^{1}$, Mark Kevin P. Devanadera ${ }^{1,2,3}$ (D), Cydee Marie V. Ramones ${ }^{4}$ (D), Aaron Joseph L. Villaraza ${ }^{4}$, \\ Leonardo A. Guevarra Jr.1,2 (D), Myla R. Santiago-Bautista1,2,3* (D), Librado A. Santiago ${ }^{1,2,3}$ (D) \\ 1Department of Biochemistry, Faculty of Pharmacy, University of Santo Tomas, Manila, Philippines, 1008. \\ ${ }^{2}$ Research Center for Natural and Applied Sciences, University of Santo Tomas, Manila, Philippines, 1015. \\ ${ }^{3}$ The Graduate School, University of Santo Tomas, Manila, Philippines, 1015. \\ ${ }^{4}$ Institute of Chemistry, College of Science, University of the Philippines Diliman, Quezon City, Philippines, 1101.
}

\section{Keywords:}

Philippine spider venom

Spider venoms

Phlogiellus bundokalbo

Neurological diseases

* Correspondence: mrsantiago@ust.edu.ph https://doi.org/10.1590/1678-9199-JVATITD-2021-0009 Received: 24 January 2021; Accepted: 31 March 2021; Published online: 28 June 2021

\begin{abstract}
Background: Spider venom is a rich cocktail of neuroactive compounds designed to prey capture and defense against predators that act on neuronal membrane proteins, in particular, acetylcholinesterases (AChE) that regulate synaptic transmission through acetylcholine (ACh) hydrolysis - an excitatory neurotransmitter - and betasecretases (BACE) that primarily cleave amyloid precursor proteins (APP), which are, in turn, relevant in the structural integrity of neurons. The present study provides preliminary evidence on the therapeutic potential of Phlogiellus bundokalbo venom against neurodegenerative diseases.

Methods: Spider venom was extracted by electrostimulation and fractionated by reverse-phase high-performance liquid chromatography (RP-HPLC) and characterized by matrix-assisted laser desorption ionization-time flight mass spectrometry (MALDITOF-MS). Neuroactivity of the whole venom was observed by a neurobehavioral response from Terebrio molitor larvae in vivo and fractions were screened for their inhibitory activities against $\mathrm{AChE}$ and BACE in vitro.

Results: The whole venom from P. bundokalbo demonstrated neuroactivity by inducing excitatory movements from T. molitor for $15 \mathrm{~min}$. Sixteen fractions collected produced diverse mass fragments from MALDI-TOF-MS ranging from 900-4500 Da. Eleven of sixteen fractions demonstrated AChE inhibitory activities with $14.34 \%( \pm 2.60 \mathrm{e}-4)$ to $62.05 \%$ ( \pm 6.40e-5) compared with donepezil which has $86.34 \%$ ( $\pm 3.90 \mathrm{e}-5)$ inhibition $(\mathrm{p}>0.05)$, while none of the fractions were observed to exhibit BACE inhibition.
\end{abstract}


Furthermore, three potent fractions against AChE, F1, F3, and F16 displayed competitive and uncompetitive inhibitions compared to donepezil as the positive control.

Conclusion: The venom of $P$. bundokalbo contains compounds that demonstrate neuroactivity and anti-AChE activities in vitro, which could comprise possible therapeutic leads for the development of cholinergic compounds against neurological diseases.

\section{Background}

Spider venoms constitute a diverse and complex cocktail of compounds that are employed for defense or predatory purposes. They contain several forms of molecules such as organic compounds, linear cytolytic peptides, disulfide-rich peptides (DRPs), and enzymes that act as neurotoxic cabals and synergistically target numerous types of neuronal membrane proteins such as receptors, ion channels, transporters, and enzymes to cumulatively paralyzed their prey or predator [1]. Therefore, the diverse pharmacological targets of spider and other animal venoms have been medically used as drugs to modulate pain and other neurological conditions. To some extent, other animal venoms were also applied to treat hypertension, diabetes, blood coagulation, pain and envenomation, which are commercially available as drugs such as exenatide from gila monsters (Helodema suspectum), captopril from Brazilian pit vipers (Bothrops jararaca), bivalirudin from medicinal leechs (Hirudo medicinalis), ziconitide from the cone snails (Conus magus), fibrin sealant from South American rattlesnakes (Crotalus durissus), and apilic antivenom from melittin and PLA 2 from Africanized honeybees (Apis mellifera) [1-9].

Moreover, there is an increasing interest in utilizing venoms to develop compounds that target neurodegenerative diseases, such as Alzheimer's disease (AD). AD is a multifactorial neurodegenerative disorder that involves memory and cognitive deterioration in individuals leading to their incapability to carry out simple activities [10,11]. Intrinsic and extrinsic etiologies such as aberrations in brain metabolism, inflammation, genetic mutations, oxidative damage, and neurotransmitter dysfunction involving several cytosolic and membrane proteins act in a concerted and cooperative manner that contribute to the formation and aggregation of insoluble amyloid-beta $(\mathrm{A} \beta)$ and hyperphosphorylated microtubule binding-tau proteins into senile plaques and neurofibrillary tangles, respectively. These events primarily drive increasing cellular stress, resulting in neuronal cell death at initial brain regions, particularly the cerebral cortex, basal ganglia, thalamus, and hippocampus [12]. Afterwards, these proteins are endocytosed to other healthy neurons and subsequently drive neuronal toxicity and death. Thus, this results in loss of neurons that phenotypically leads to disrupted cognitive and motor responses from afflicted patients [13].

Additionally, one of the prominent postulations of the disease progression of $\mathrm{AD}$ is cholinergic hypothesis wherein the decline of an excitatory, acetylcholine (ACh), results in deterioration of cognitive and motor activities in patients [14]. ACh transmits information by interacting at post-synaptic acetylcholine receptors (AChR), which promotes downstream signaling to deliver further response to other neurons. Regulation of ACh is conducted by a post-synaptic acetylcholinesterase (AChE) to modulate synaptic transmission $[15,16]$. However, in neurodegenerative diseases, an increase in activities of AChE immediately decreases ACh transmission, which results in a lack of downstream signaling in post-synaptic neurons that promotes aberrant activities of beta-secretase (BACE) [17].

$\mathrm{BACE}$ is an intracellular transmembrane protease that initiates the cleavage of amyloid precursor proteins (APP) into insoluble and neurotoxic $A \beta$ and tau proteins [17]. Aside from this, the need for elevated ACh levels is mandatory to counteract the lack of surviving neurons in neurodegenerative disease states $[12,14,15]$. Hence, this idea provides fundamental insights to develop AChE and BACE inhibitors to modulate disease progression $[18,19]$. However, the creation of safe and therapeutic BACE inhibitors is still a challenge in development, while prolonged use of AChE inhibitors might produce toxic metabolites and other side effects that can be detrimental to the patient $[20,21]$.

This is the reason for developing potent, specific and nontoxic compounds that target upstream membrane proteins that are involved in normal neuronal activities to treat the disease progression [22]. Therefore, spider venom peptides, which primarily target neuronal membrane proteins to modulate the nervous system of their prey or predators, present an attractive strategy to repurpose such compounds to target relevant structural and functional equivalent membrane proteins in humans associated with neurodegenerative diseases [16,23-25].

The Philippines, an archipelago of some $\sim 7,100$ islands in Southeast Asia, is teeming with diverse venomous spiders that are yet to be utilized for the discovery and development of peptide drugs against neurodegenerative diseases [26,30]. Among the endemic spiders of interest is Phlogiellus bundokalbo (Figure 1), a tarantula belonging to Theraphosidae family first described by Barrion and Litsinger [25]. Most of the studies on this spider were limited to ecological, morphological, and taxonomical approaches [26-34]. However, research on the biological activities of its venom only focused on its cytotoxic and anti-cancer activities [35-37]. For instance, the venom of Phlogiellus bundokalbo exhibited cytotoxicity on human lung adenocarcinoma (A549) cells and human breast adenocarcinoma (MCF-7) cells by producing pro-oxidative radicals that impair mitochondrial membrane potential, activate caspases and initiate nuclear fragmentation [35-37]. For this reason, rigorous and extensive biomedical research is required to study the 
venom from $P$. bundokalbo in order to expand its utility for drug discovery and development towards neurodegenerative therapeutics. In fact, venoms from other notable species of spiders have demonstrated such activities. Two toxins from Phoneutria nigriventer, namely $\mathrm{PhTx} 3-1$ and $\mathrm{PhTx} 4-5-5$, were found to be neuroprotective and exhibit memory improvement in mice hippocampal neuronal slices administered with A $\beta$ [38-40].

Moreover, $\mathrm{PhkV}$, a peptide isolated from the same spider, has demonstrated antinociceptive activities through AChE inhibition which modulates the cholinergic system [41]. Aside from this, psalmotoxin (PcTx1) from Psalmopoeus cambridgei is currently being assessed for neuroprotective activities against neuronal acid sensing ion channels (ASICs) in preclinical studies to be suitable drug to treat hemorrhagic and ischaemic stroke [42].

Therefore, this present study aims to evaluate the neuroactivity in vivo and inhibitory properties against $\mathrm{AChE}$ and BACE in vitro of fractional constituents from the venom of $P$. bundokalbo, providing an initial overview on the therapeutic potential of this venom from for application against neurodegenerative diseases.

\section{Methods}

\section{Materials and equipment}

All reagents and chemicals that were used in the study were analytical grade and bought from RCL Labscan, Thailand; Mym Biological Technology Company, Hi-Media Laboratories, India; Sigma-Aldrich Life Sciences; LaserBio Labs, France; Macron Fine Chemicals, Cayman Chemical Company, USA and Molecular Probes Invitrogen, USA. On the other hand, Waters Alliance e2695 RP-HPLC system equipped with w2489 UVVIS spectrophotometer and Agilent Eclipse PlusC18 analytical column $(5 \mu \mathrm{m}, 5.6 \times 150 \mathrm{~mm}$, pore size-100 $\mathrm{A})$ were used for the fractionation of whole spider venom. Lyophilization was done using Sim International FD5-series freeze dryer. Aside from this, ThermoFisher Multiskan microplate spectrophotometer and Promega GloMax Explorer multimode microplate reader was used for the colorimetric enzymatic assays. Moreover, Shimadzu Axima Confidence Linear/Reflectron MALDI-TOF-MS system was used to determine the masses from the spider venom fractions.

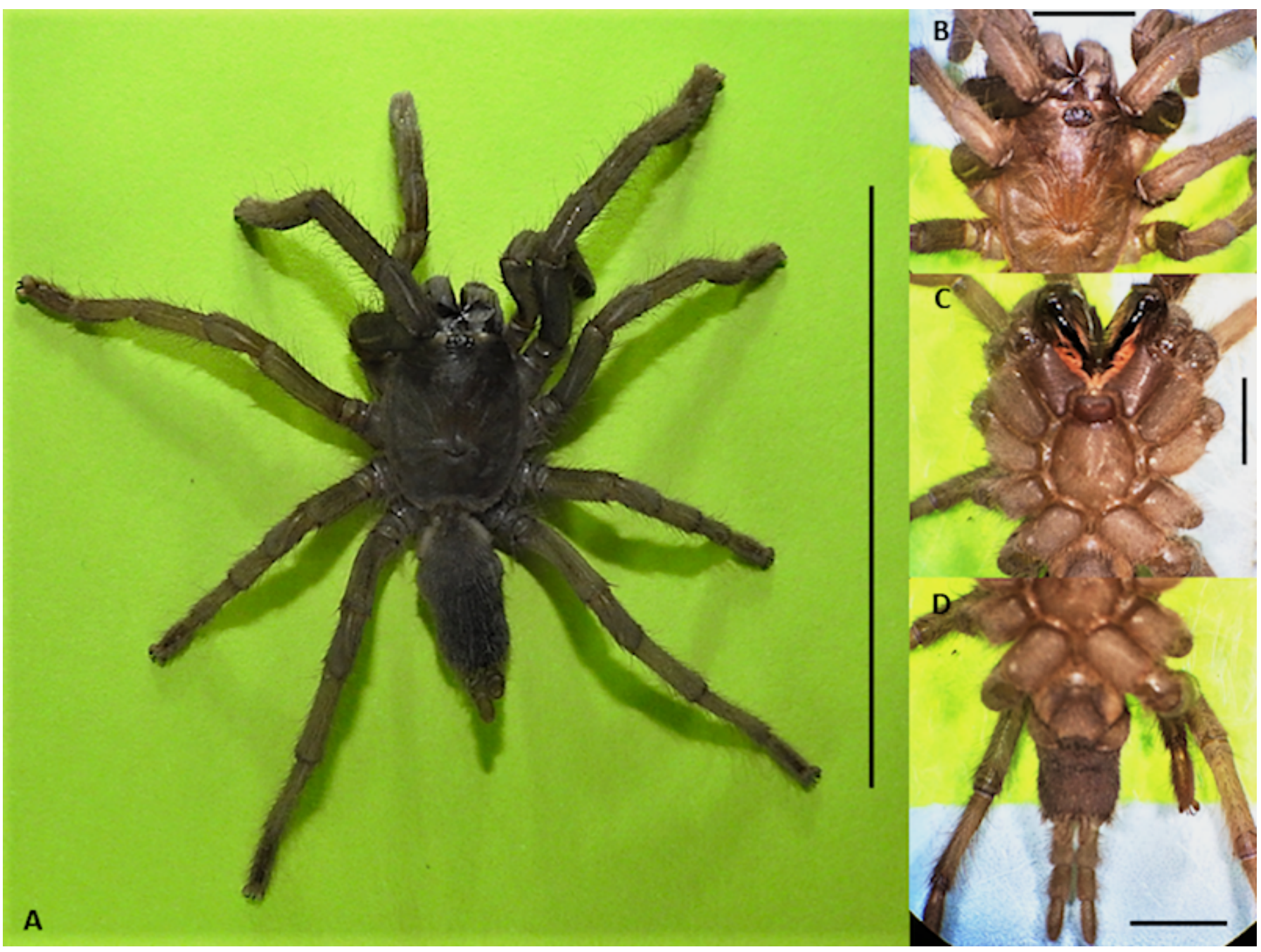

Figure 1. A sample of Phlogiellus bundokalbo that is used for venom collection and taxonomic identification. (A) Dorsal view, habitus, Bagacay, Surigao Island, Province of Surigao del Norte, Mindanao, Philippines. (B) Carapace and eyes, dorsal view. (C) Sternum, labium, maxilla, and coxae, ventral view. (D) Abdomen, ventral view. Scale bar $-30 \mathrm{~mm}$ for (A) and $5 \mathrm{~mm}$ for (B), (C), and (D). 


\section{Spider collection, rearing, maintenance and identification}

The spiders were collected from the cave areas in Bagacay, Surigao, Mindanao, Philippines (Figure 2) through hand-grabbing and entrapments in their cave systems. The spiders were enclosed in $35 \times 25 \times 10 \mathrm{~cm}$ plastic boxes containing moist coconut coir beddings [43]. Then, they were maintained at room temperature with a twelve-hour light and dark cycle at the Biochemistry Laboratory of UST Central Laboratory. Afterwards, the spiders were fed with a cave dwelling cockroach Pycnoscelsus striatus once per week and provided with water ad libitum [33]. A group of the collected spiders (Figure 1) were submitted to the Museum of Natural History of the University of the Philippines Los Baños for proper identification and authentication by Dr. Aimee Lynn Barrion-Dupo through assessment of their morphological features and characteristics.

\section{Whole venom extraction from Phlogiellus bundokalbo}

Spiders were initially anesthetized by carbon dioxide $\left(\mathrm{CO}_{2}\right)$. Whole venom was collected at the chelicerae through electrostimulation at a nonlethal voltage of $35 \mathrm{~V}$ in the microtubes and washed with $100 \mu \mathrm{L}$ distilled $\mathrm{H}_{2} \mathrm{O}$ followed by centrifugation. Then, the whole venom was run in RP-HPLC, lyophilized, and stored under $-20^{\circ} \mathrm{C}$ prior to assay [43].

\section{Reverse-phase high performance liquid chromatography fractionation}

Five microliters of $5.73 \mathrm{mg} / \mathrm{mL}$ of whole venom were diluted by $195 \mu \mathrm{L} 0.1 \%$ trifluoroacetic acid (TFA) in distilled $\mathrm{H}_{2} \mathrm{O}$ in a vial with a conical insert, fractionated using $\mathrm{C} 18$ analytical column as stationary phase and run through a $0-95 \%$ linear gradient elution system with a flow rate of $1 \mathrm{~mL} / \mathrm{min}$ for 105 min using $0.1 \%$ TFA and distilled $\mathrm{H}_{2} \mathrm{O}$ and $0.1 \%$ TFA in $90 \%$ acetonitrile (ACN) solvent system. The detection of the peaks was monitored at 215 and $280 \mathrm{~nm}$, and the corresponding fractions were collected based on the peaks observed. Afterwards, the fractions were lyophilized and stored at $-20^{\circ} \mathrm{C}$ refrigerator.

\section{Peptide determination and quantification}

Colorimetric confirmation from bicinchoninic acid (BCA) assay was employed in the whole and fractionated venom. A positive test from this assay results in a color change from colorless to deep purple. The reaction mixture contained $500 \mu \mathrm{L}$ of BCA working reagent and $10 \mu \mathrm{L}$ of the sample. Then, the reaction mixtures were incubated at $60^{\circ} \mathrm{C}$ for $30 \mathrm{~min}$ and the absorbance was read at $562 \mathrm{~nm}$ using a UV-Vis spectrophotometer [44]. The crude whole venom sample was also quantified in BCA assay using increasing concentrations of bovine serum albumin (BSA) $\left(\mathrm{R}^{2}=0.992\right)$.

\section{Matrix assisted light desorption ionization-time of flight (MALDI-TOF) mass spectrometry of peptide fractions and manual curation in ArachnoServer toxin database}

MALDI-TOF-MS characterization of spider venom fractions was conducted at the Institute of Chemistry, University of the Philippines Diliman. Following the standard protocol from the manufacturer for sample preparation, $1 \mathrm{mg} / \mathrm{mL}$ of

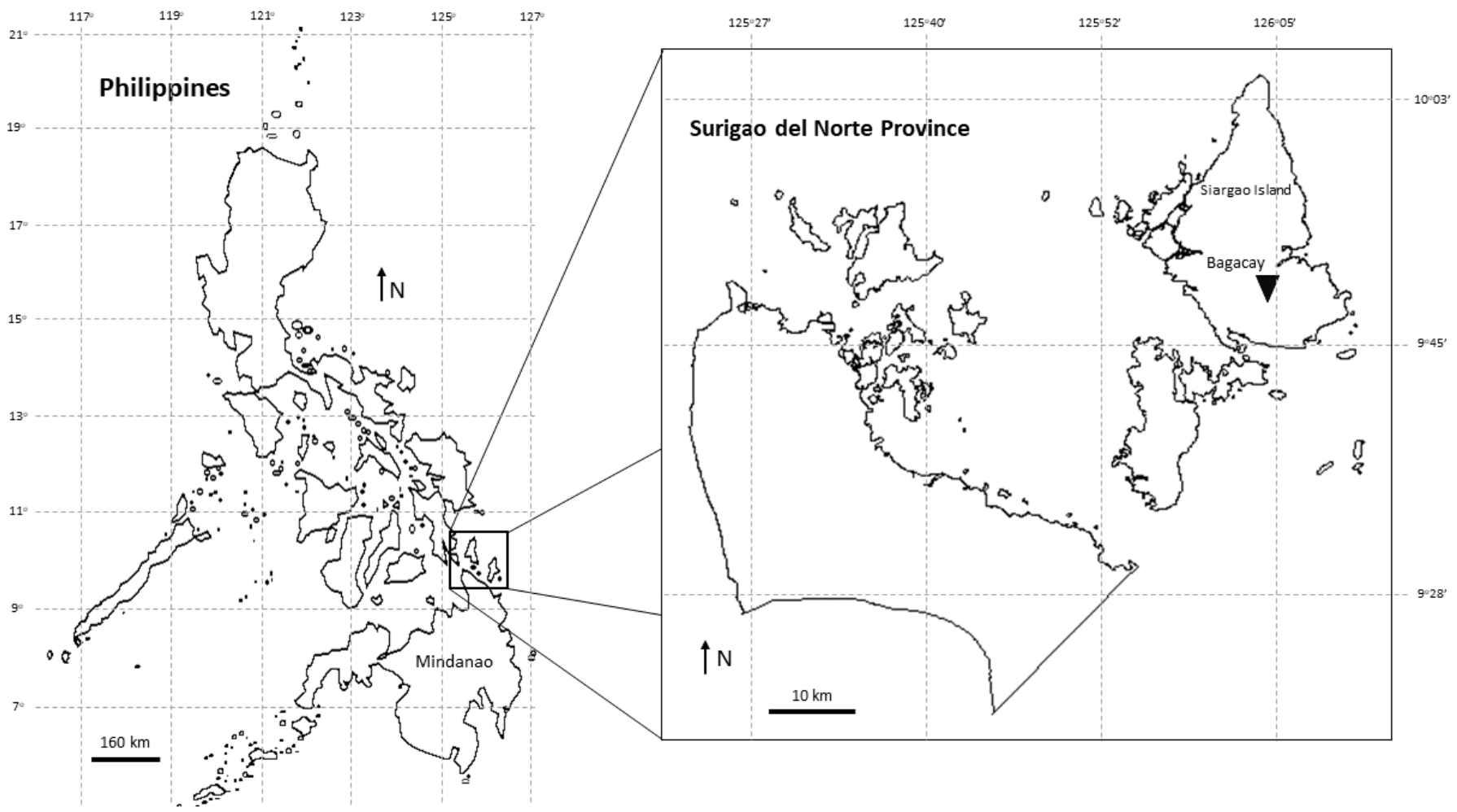

Figure 2. Sampling site of Phlogiellus bundokalbo in Bagacay, Surigao Island, Province of Surigao del Norte, Mindanao, Philippines. 
spider venom fractions were dissolved in $10 \mathrm{mg} / \mathrm{mL}$ a-cyano4-hydroxycinnamic acid (CHCA) matrix solution in the MALDI plate. Then, the plated samples were air-dried at room temperature before the sample plate was loaded and analyzed into the Shimadzu Axima Confidence Linear/Reflectron MALDITOF-MS system at positive ionization mode.

All spectrometric data were processed and analyzed using Shimadzu Biotech Launchpad ${ }^{\mathrm{TM}}$ software, v.2.9. Spectral profiles were obtained with detection in the positive ion mass mode at a laser frequency of $50 \mathrm{~Hz}$ and within a mass range from 1000-4500 Da. MALDI was produced using pulsed laser light $(337.1 \mathrm{~nm}$, 3 -ns pulse width) generated by a nitrogen laser with are petition rate of $60 \mathrm{~Hz}$. Each spectrum resulted from the accumulation of data from 100 profiles, where each profile is generated from a minimum of 5 laser shots. A bias voltage of 45-80 V was applied to the sample plate. Acceleration voltage was $10 \mathrm{kV}$. External mass calibration was performed daily using the MALDI-TOF peptide mix calibration standard (757-3,657 Da) from Shimadzu.

A database search for detected peptide masses from the venom fractions of $P$. bundokalbo was conducted by manual curation of related deposited peptides to Arachnoserver [45].

\section{Screening for beta-secretase inhibitory activities}

The assay was performed based on the study of Je and Kim [46] and the instructions from Sigma-Aldrich Life Sciences, USA, with some modifications. The activity of BACE is dependent on the fluorescence intensity of the peptide substrate containing EDANS-DABCYL reporter molecules [H-RE(EDANS) EVNLDAEFL(DABCYL)R-OH], which are the donor and quencher, respectively.

A $10 \mu \mathrm{L}$ of $100 \mu \mathrm{g} / \mathrm{mL}$ each sample (whole venom and fractionated venom) and negative control (distilled $\mathrm{H}_{2} \mathrm{O}$ ) were added to each well of a 96-microwell plate and mixed with $90 \mu \mathrm{L}$ of $50 \mathrm{mM}$ sodium acetate buffer at $\mathrm{pH} 4.5,2 \mu \mathrm{L}$ of BACE substrate, and $4 \mu \mathrm{L}$ of $1.0 \mathrm{U} / \mathrm{mL}$ of active BACE. The mixture was incubated for $60 \mathrm{~min}$ at $37^{\circ} \mathrm{C}$ in dark. The ratiometric fluorescence at $\lambda_{\mathrm{em}}=$ 495-510 $\mathrm{nm}$ and $\lambda_{\mathrm{ex}}=335-355 \mathrm{~nm}$ of the samples was read in a fluorescence microplate reader. The negative control for the assay was $50 \mathrm{mM}$ acetate buffer at $\mathrm{pH} 4.5$ in the enzymatic reaction mixture. A BACE inhibitory activity graph was established to determine the percentage of BACE inhibition per venom fraction compared to the negative control $[46,47]$.

\section{Screening and characterization for acetylcholinesterase inhibitory activities}

AChE inhibition assay was adopted from the protocol of Ellman et al. [48] with modifications. The activity of AChE is dependent on the product formation of thiocholine from acetylthiocholine iodide (ATCl) which is detected by Ellman's reagent or 5,5'-dithiobis-(2-nitrobenzoic acid) (DTNB) to form 5-thio-2-nitrobenzoic acid (TNB), a yellow-colored compound that can be detected at $412 \mathrm{~nm}$ using UV-Vis spectrophotometer.

For screening of AChE inhibitory activities, $25 \mu \mathrm{L}$ of $100 \mu \mathrm{g} /$ $\mathrm{mL}$ each sample (whole venom, fractionated venom, Donepezil, distilled $\mathrm{H}_{2} \mathrm{O}$ ) were added to each well in a 96-well microplate and mixed with $50 \mu \mathrm{L}$ of $50 \mathrm{mM}$ Tris- $\mathrm{HCl}$ buffer at $\mathrm{pH}$ 8.0, $25 \mu \mathrm{L}$ of $1.5 \mathrm{mM}$ ATCl, $125 \mu \mathrm{L}$ of $3.0 \mathrm{mM}$ DTNB and $25 \mu \mathrm{L}$ of $0.51 \mathrm{U} / \mathrm{mL}$ AChE. In addition, the positive control used for the study was $400 \mu \mathrm{g} / \mathrm{mL}$ of commercial Donepezil (Aricept $t^{\oplus}$ ), a known AChE inhibitor. The blank mixture used in the assay was composed of $50 \mathrm{mM}$ Tris-HCl buffer at $\mathrm{pH} 8.9$ with $3.0 \mathrm{mM}$ DTNB. The microplate containing the mixture was incubated at room temperature for $5 \mathrm{~min}$ and read at $412 \mathrm{~nm}$ absorbance with $30 \mathrm{sec}$ reading time intervals. Additionally, a time-dependent product formation from the enzymatic reactions was constructed to determine the inhibitory activity of the fractions with respect to the negative control, while an AChE inhibitory activity graph was created to compare the activity of venom fractions with the negative and positive controls $[48,49]$.

The three fractions with potent anti-AChE activities were selected for competition experiments to determine the type of inhibition exhibited against $\mathrm{AChE}$ alongside the whole venom, Donepezil, and untreated $\mathrm{AChE}$ reactions through a concentration-dependent manner. The type of inhibition of each fraction was determined by comparing the Michaelis constant $\left(\mathrm{K}_{\mathrm{M}}\right)$ and maximum velocity $\left(\mathrm{V}_{\max }\right)$ values with the negative and positive controls using the kinetic graph. Lastly, an L-cysteine standard curve was established to quantify the products formed from the reactions of $\mathrm{AChE}$ and $\mathrm{ATCl}\left(\mathrm{R}^{2}=0.989\right)$.

\section{Neurophysiological evaluation of potent AChE spider venom and its fractions using Tenebrio molitor}

Evaluation of the locomotor activity of Tenebrio molitor was adapted from the study of Friedel and Nentwig [50] and Hardy et al. [51] with modifications. Five microliters of 100 $\mu \mathrm{g} / \mathrm{mL}$ sample (whole and three venom fractions) with potent activities against AChE, $400 \mu \mathrm{g} / \mathrm{mL}$ Donepezil (positive control) and $0.9 \%$ NSS (negative control) were used and administered between the sutures of the third metathoracic segment of each worm using Hamilton microsyringe. Rate of movements and locomotion activity were scored and observed for $15 \mathrm{~min}$ post-injection with 2-min interval to evaluate the effect of administration of each sample to the worm. The scoring was graded from 1 to 4 , and the criteria were as follows: 4-severe, paralytic movements, insect cannot right itself; 3 - continuous, twisting movements; 2 - periodic, contracting movements and 1- little to no movement. A score versus time plot were established for this assay $[50,51]$.

\section{Statistical analysis}

Microsoft Excel version 2019, pH Stat, and GraphPad Prism 6 were used for the different statistical analyses throughout the study. Each of the assays was conducted in triplicates with varying trials for the computation of mean and standard error mean (SEM). One-way analysis of variance (ANOVA) was employed to determine the significant differences between the treated and untreated groups wherein p-values $<0.05$ were considered statistically significant at $95 \%$ confidence interval. 


\section{Results}

\section{Chromatographic profile and quantification of Phlogiellus bundokalbo whole spider venom}

The chromatogram in Figure 3 shows the whole spider venom profile which was fractionated by $\mathrm{C} 18$ column using $\mathrm{ACN}$ and TFA in $\mathrm{dH}_{2} \mathrm{O}$ as solvent system through gradient elution for 105 min. Also, the peaks represent different compounds detected at 215 and $280 \mathrm{~nm}$ predominantly indicating the presence of various forms of peptides, proteins, acylpolyamines, biogenic amines and nucleic acids, respectively. Based on the chromatographic profile, the whole venom generated 16 peaks as indicated by their retention times. The elution behavior of each peak constituent is influenced by the composition of the solvent system, ACN and TFA in $\mathrm{H}_{2} \mathrm{O}$, which were semi-polar in nature and affected the elution profile of the whole venom. The peak intensities indicate differences in levels of compounds present in the venom that are principally detected in the semi-polar region.

MALDI-TOF-MS mass distribution peptide profiles of Phlogiellus bundokalbo spider venom and its fractions

The diversity of compounds from the whole and fractionated venom from $P$. bundokalbo was explored through MALDI-TOFMS and was measured according to their monoisotopic oxidized mass $[\mathrm{M}+\mathrm{H}]^{+}$. Figure $4 \mathrm{~A}$ shows the mass spectra of whole spider venom wherein intense signals from the peptides are detected from $900 \mathrm{Da}-4000 \mathrm{Da}$. Moreover, the crude sample was further fractionated and characterized by mass spectrometry to account for peptides that can be swamped out from the whole venom $[52,53]$. Results show that 319 peptides were detected from the fractionated whole venom ranging from $1000 \mathrm{Da}-4500 \mathrm{Da}$ which were classified into $500 \mathrm{Da}$ intervals as shown in Figure $4 \mathrm{~B}$ and $4 \mathrm{C}$ Furthermore, the complexity of $P$. bundokalbo venom was plotted in a 3D landscape as shown Figure 4D wherein pronounced intensities ranging from $1000 \mathrm{Da}-2500 \mathrm{Da}$ are observed in fractions 1-6 and 11-16, and $3000 \mathrm{Da}-4500 \mathrm{Da}$ in fractions 7-10 [54].

\section{Screening for BACE inhibitory activities of $P$. bundokalbo spider venom and its fractions}

The whole and fractionated venom samples were screened for BACE inhibitory activities in comparison with the negative control or the untreated BACE reaction solution. However, most of the venom-treated samples demonstrated negative percentage inhibition which suggests that the fractional constituents of the spider venom did not exhibit BACE inhibition as indicated in Figure 5. Moreover, only F7 have shown weak inhibition to the enzyme compared to the untreated enzyme reaction and whole venom.

\section{Screening and characterization of AChE inhibitory activities in vitro of Phlogiellus bundokalbo spider venom and its fractions}

The venom fractions were screened for AChE inhibitory activities in vitro compared to the whole venom, Donepezil (positive control), and untreated AChE reaction (negative control). Out of the 16 fractions, 11 of them exhibited anti-AChE activities, as demonstrated in Figure 6. Furthermore, F1, F3 and F16 showed the highest percentage of inhibition on AChE activity with values of $48.89 \%( \pm 1.31 \mathrm{e}-4), 54.33 \%( \pm 1.21 \mathrm{e}-4)$ and $62.05 \%$ $( \pm 6.40 \mathrm{e}-5)$ respectively. In addition, the whole venom has an AChE percentage inhibition of $57.97 \%( \pm 1.99 \mathrm{e}-4)$, which is slightly lower than F16. In contrast, Donepezil $(400 \mu \mathrm{g} / \mathrm{mL})$ exhibited the highest AChE inhibitory activity of $86.34 \%$ $( \pm 3.90 \mathrm{e}-5)$ compared to the fractionated and whole venom. A 5-min time-dependent kinetic graph showed in Figure 7 further validates the different responses of the whole venom, fractionated venom, and Donepezil on AChE activity. Fractions 1-4, 7, 11-16 showed an AChE kinetic curve below the kinetic curve of the negative control, while fractions 5, 6, 8 to 10 showed otherwise as represented in Figure $7 \mathrm{~A}$ and $7 \mathrm{~B}$, respectively. Notably, the whole venom and Donepezil have exhibited a linear trend of AChE kinetic activity below the untreated enzyme curve which is also lower than the venom fractions indicating strong inhibition.

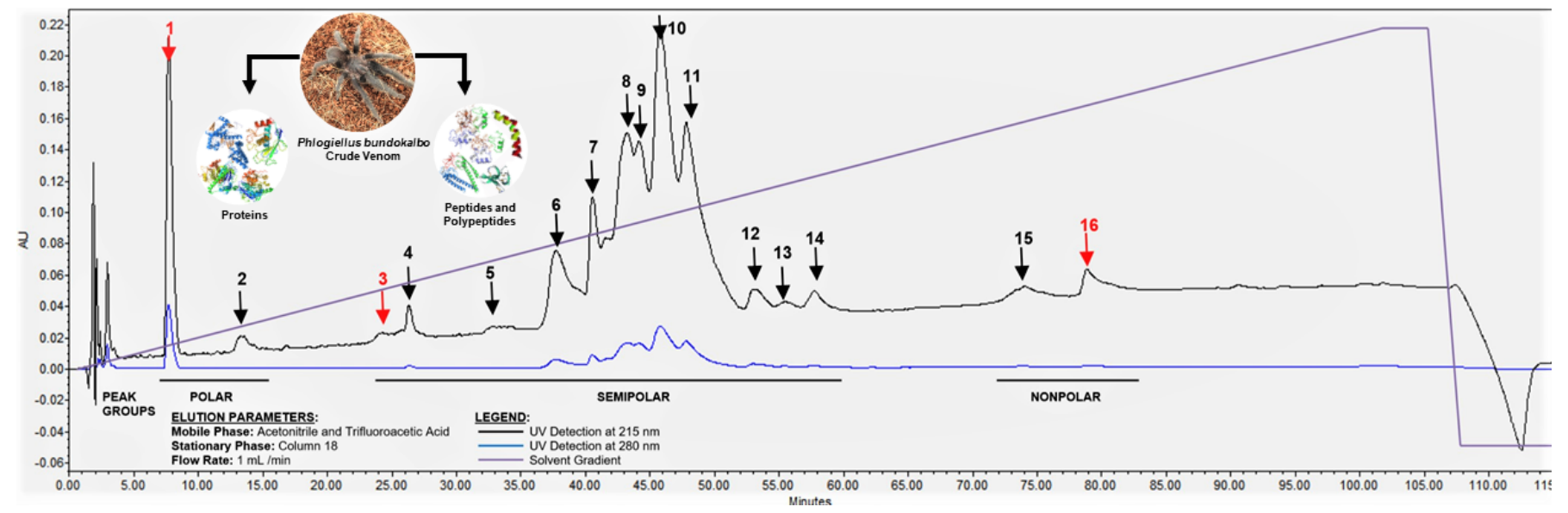

Figure 3. RP-HPLC profile of whole spider venom from Philippine tarantula. Arrows indicate the collected fractions with red color showing potent acetylcholinesterase inhibitory bioactivity. 

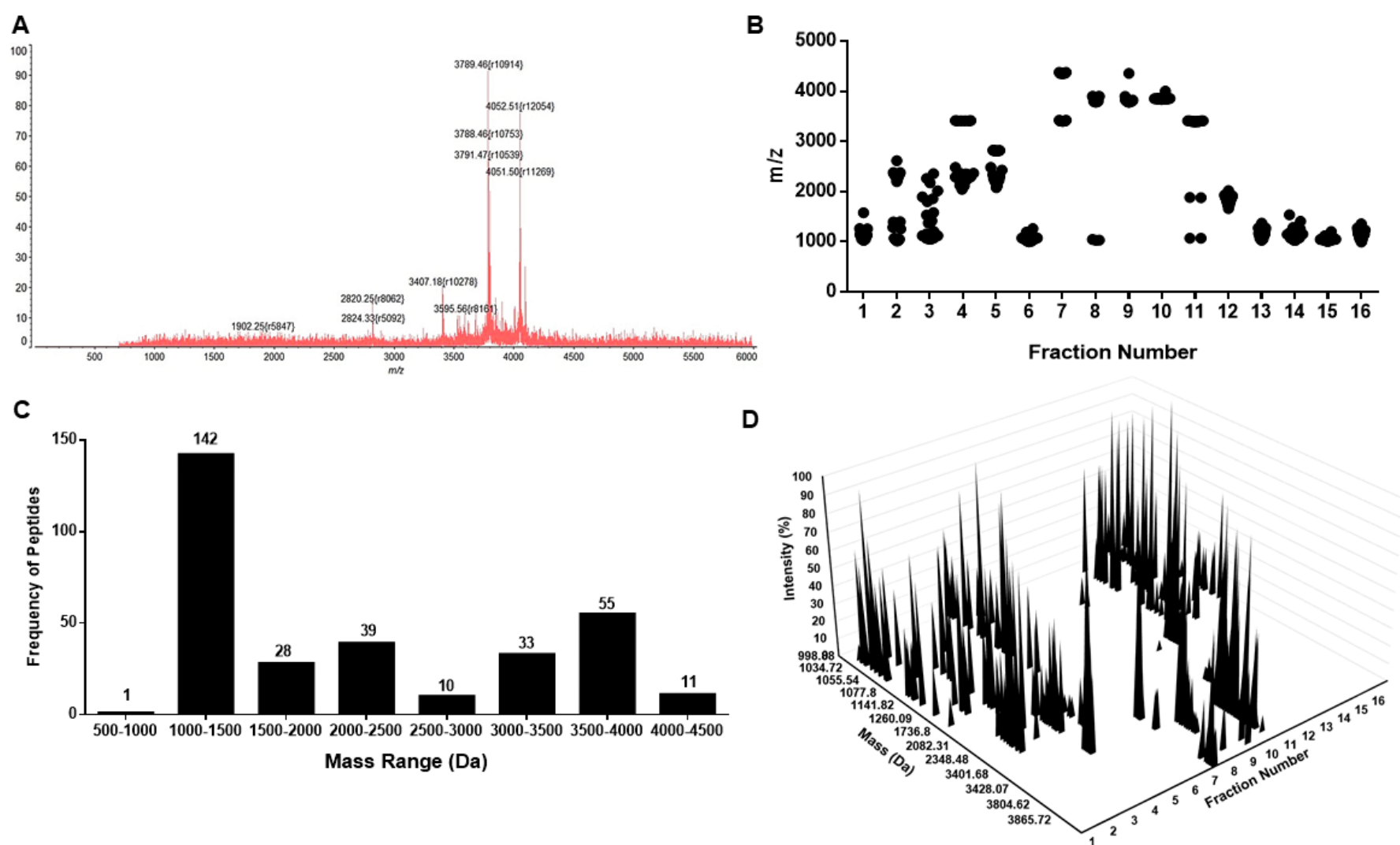

Figure 4. Distribution of peptide masses from Phlogiellus bundokalbo whole venom. (A) MALDI-TOF-MS spectrum of whole spider venom. (B) Distribution of venom peptide fractions as a function of mass-to-charge ratio collected from the RP-HPLC and compared with MALDI-TOF-MS spectra. (C) Histogram peptide frequency distributed and sorted according to $500 \mathrm{Da}$ interval. (C) The 3D venom landscape of Phlogiellus bundokalbo venom is plotted according to the percentage area of peak intensity, mass-to-charge ratio from MALDI-TOF-MS and fraction number from RP-HPLC.

\section{Beta-Secretase Inhibition of Spider Venom}

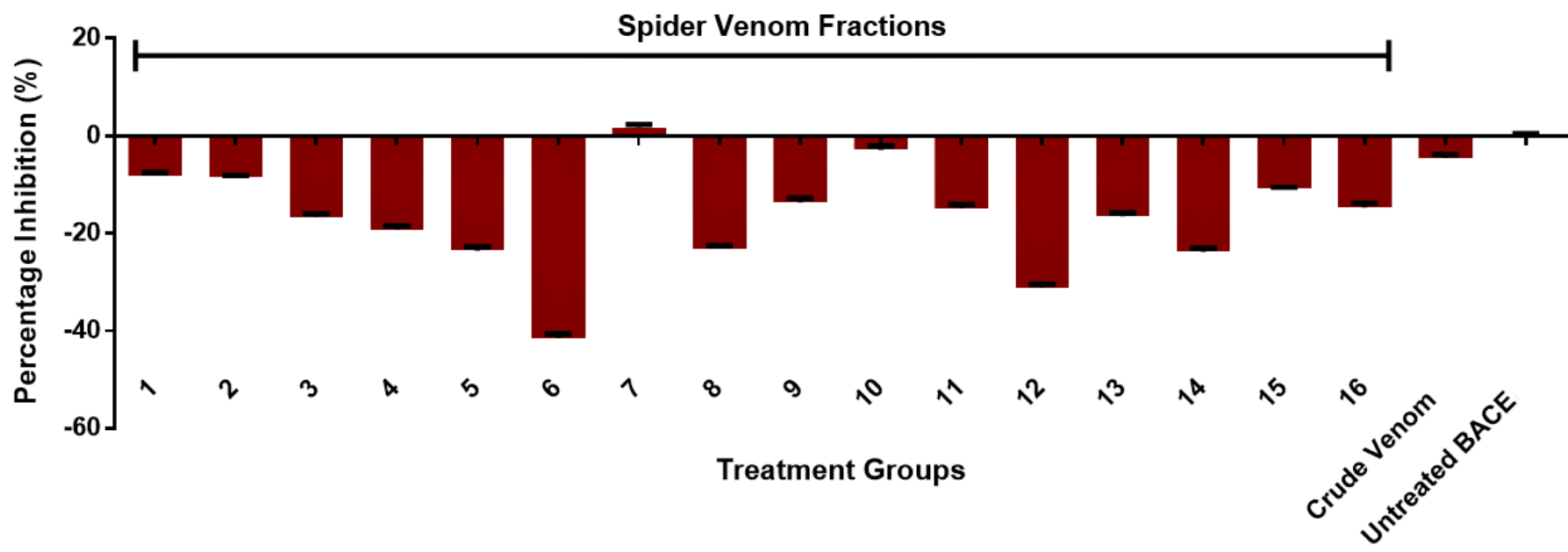

Figure 5. Screening for BACE inhibitory activities of whole and fractionated venom compared to untreated BACE reactions. Data is reported as mean \pm SE (bars) $(n=3)$. 


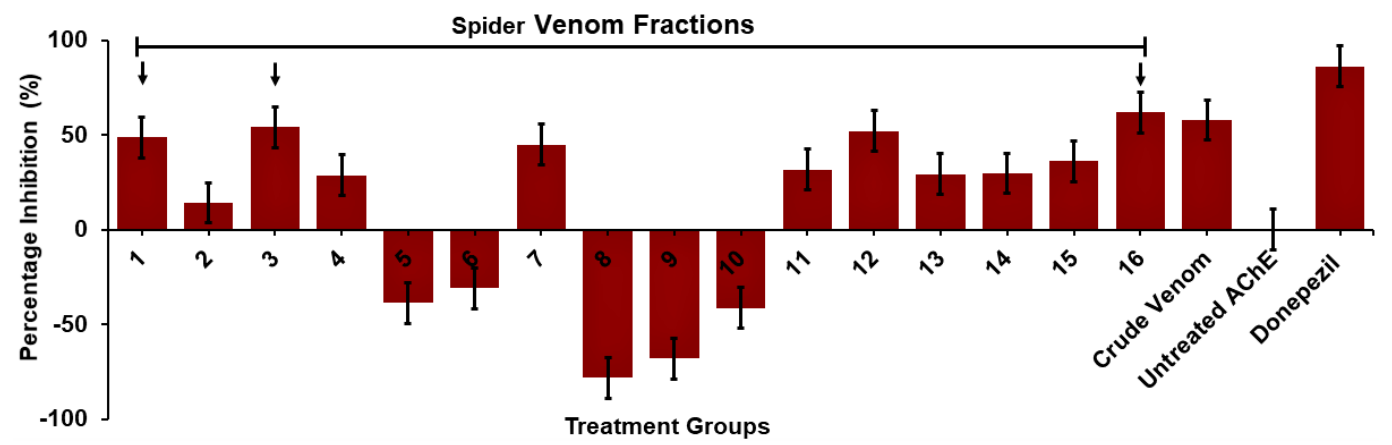

Figure 6. Screening for AChE inhibitory activities of whole and fractionated venom compared to untreated AChE reactions and Donepezil. Data are reported as mean \pm SEM (bars). Note: ${ }^{*} p<0.05$ significant differences against the negative control value (untreated AChE) $(n=3)(p=0.965)$. Red arrows indicate the fractions with the highest AChE inhibitory activity.
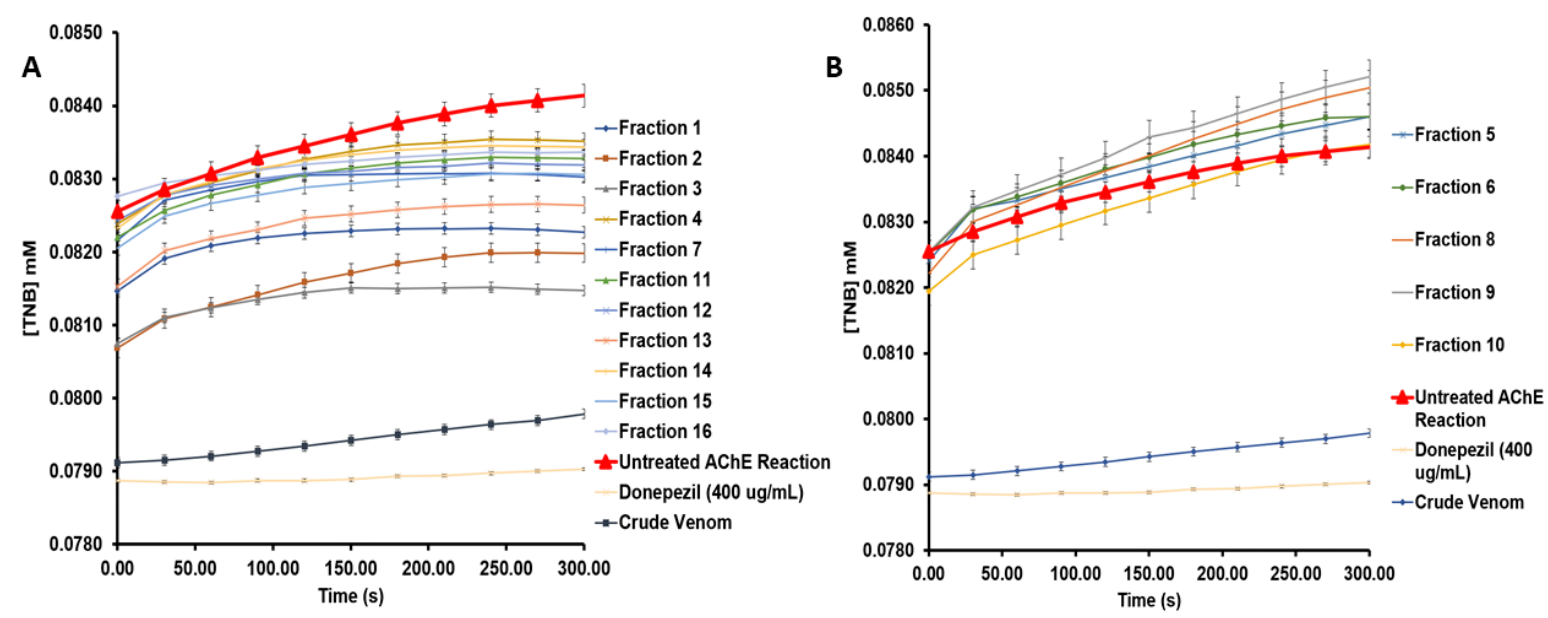

Figure 7. Time-dependent $A C h E$ kinetic analysis of $(\mathbf{A})$ anti-AChE and (B) pro-AChE of venom fractions alongside with whole venom, Donepezil, and untreated $A C h E$ reaction. Data are reported as mean \pm SEM (bars) $(n=3)$.

Moreover, F1, F3, and F16 exhibited potent anti-AChE activity which was also selected for substrate competition experiments to characterize the possible mode of inhibition and binding affinity to AChE against Donepezil and whole venom. Graphical results reported in Figures 8A and 8B showed that Donepezil, whole venom, and F3 exhibited competitive inhibition. In contrast, F1 and F16 exhibited uncompetitive inhibition as supported by $\mathrm{K}_{\mathrm{M}}$ and $\mathrm{V}_{\max }$ values derived from the Michaelis-Menten and LineaweaverBurke kinetics compared to the untreated $\mathrm{AChE}$ reactions.

The kinetic parameters Michaelis constant $\left(\mathrm{K}_{\mathrm{M}}\right)$ measures the affinity of substrate concentrations at $1 / 2$ of the maximum velocity $\left(\mathrm{V}_{\max }\right)$ of an enzyme. The corresponding values are shown in Table 1 wherein significant kinetic inhibition was observed on the spider venom and Donepezil with respect to the untreated AChE reaction.

\section{Neurophysiological evaluation via T. molitor locomotion of Phlogiellus bundokalbo whole venom and its fractions}

Similarly, F1, F3, F16, whole venom, and Donepezil were administered between the sutures of the third metathoracic segment of T. molitor and observed their locomotory changes concerning the larvae administered with $0.9 \%$ normal saline solution (NSS) for $15 \mathrm{~min}$ as represented in Figure 9. Results showed that all the treated worms exhibited different levels of immediate excitation attributed to their physiological, excitatory, and motor activities upon administration of the sample.

\section{Manual curation of peptide masses from $P$. bundokalbo venom}

Database search of the monoisotopic oxidized peptide masses of the whole and fractionated spider venom from P. bundokalbo showed that all the peptide masses were not similar to masses of 3 isoforms of peptides from Phlogiellus sp. recorded on Arachnoserver which are $\mu$-theraphotoxin-Phlola (4103.79 $\mathrm{Da}), \mu$-theraphotoxin-Pholb (4137.78 Da), and $\mu$-theraphotoxinPhlo2a (N-terminal fragment) $(3276.33 \mathrm{Da})[45,55,56]$. On the other hand, some of the peptides present in the whole and fractionated venom have similar masses present in the database from other species of spider that are related to P. bundokalbo by family and order as shown in Table 2 . 


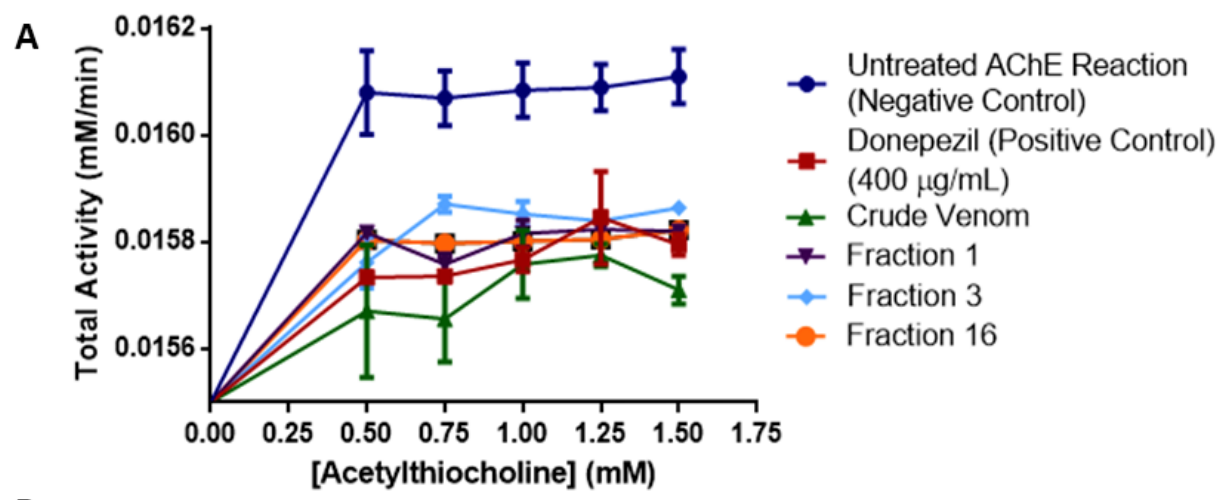

B

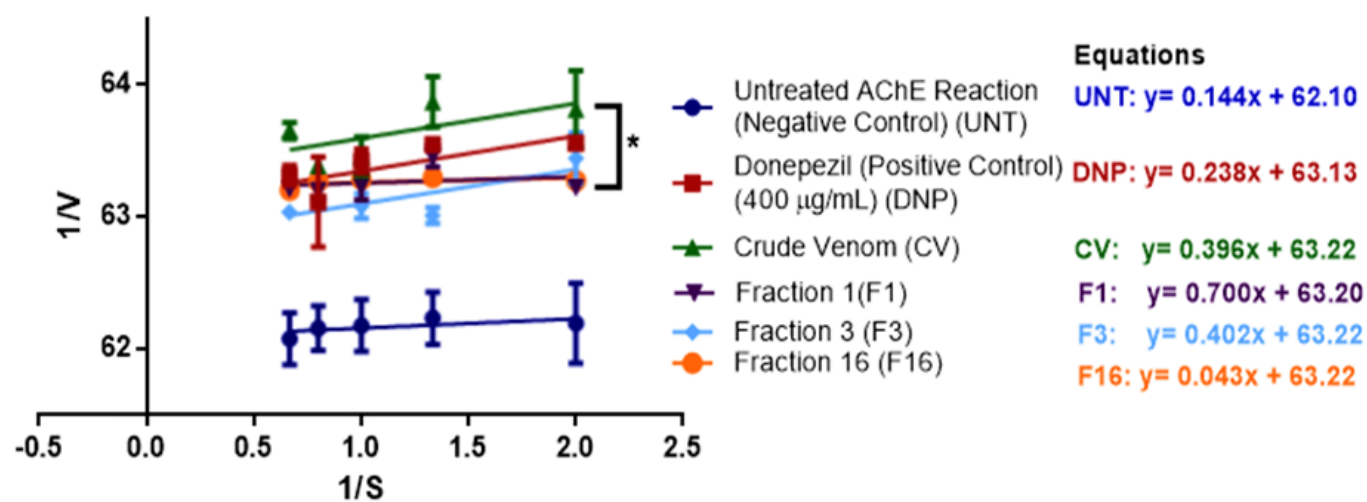

Figure 8. (A) Michaelis-Menten kinetics and (B) Lineweaver-Burk kinetics of venom fractions 1, 3, 16, whole venom in comparison with Donepezil and untreated AChE reaction. Data are reported as mean \pm SEM (bars). Note: ${ }^{*} p<0.05$ significant differences against the negative control value (untreated AChE reaction) $(n=3)(p=0.001)$.

Table 1. Results of inhibition of venom fractions $1,3,16$ and whole venom to $A C h E$ in comparison with Donepezil and untreated $A C h E$ reaction. Data is reported as mean \pm SEM. Note: ${ }^{*} p<0.05$ significant difference against the negative control value (untreated $A C h E$ reaction) $(n=3)(p=0.0008)$.

\begin{tabular}{lccc}
\hline Sample & $\mathbf{K}_{\mathbf{M}}(\mathbf{m} \mathbf{M})$ & $\mathbf{V}_{\mathbf{m a x}}(\mathbf{m} \mathbf{M} / \mathbf{m i n})$ & Type of inhibition \\
\hline Untreated AChE Reaction & $1.15 \times 10^{-3} \pm 1.5 \times 10^{-3}$ & $1.61 \times 10^{-2} \pm 3.3 \times 10^{-5}$ & - \\
Donepezil & $4.24 \times 10^{-3} \pm 2.1 \times 10^{-3}$ & $1.59 \times 10^{-2} \pm 5.6 \times 10^{-5}$ & Competitive \\
Whole venom & $4.20 \times 10^{-3} \pm 4.2 \times 10^{-3}$ & $1.58 \times 10^{-2} \pm 5.1 \times 10^{-5}$ & Competitive \\
Fraction 1 & $7.50 \times 10^{-4} \pm 5.0 \times 10^{-4}$ & $1.58 \times 10^{-2} \pm 5.4 \times 10^{-6}$ & Uncompetitive \\
Fraction 3 & $4.16 \times 10^{-3} \pm 2.4 \times 10^{-3}$ & $1.59 \times 10^{-2} \pm 4.3 \times 10^{-5}$ & Competitive \\
Fraction 16 & $5.60 \times 10^{-3} \pm 9.0 \times 10^{-5}$ & $1.58 \times 10^{-2} \pm 7.2 \times 10^{-6}$ & Uncompetitive \\
\hline
\end{tabular}

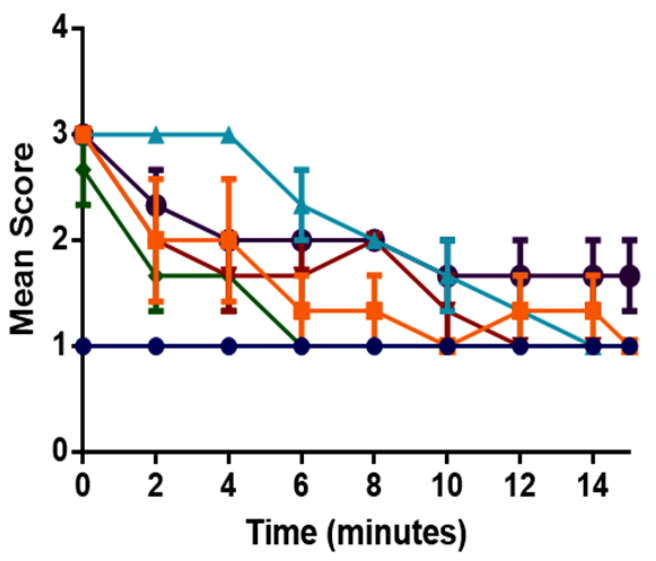

Normal Saline Solution

(Negative Control) Donepezil (Positive Control)

$(400 \mu \mathrm{g} / \mathrm{mL})$

\pm Crude Venom

$\rightarrow$ Fraction 1

Fraction 3

Fraction 16

Figure 9. Behavioral trend observed in the locomotion of T. molitor after administration of Donepezil and spider venom in comparison with $0.9 \%$ NSS Data are reported as mean \pm SEM bars $(n=3)$. 


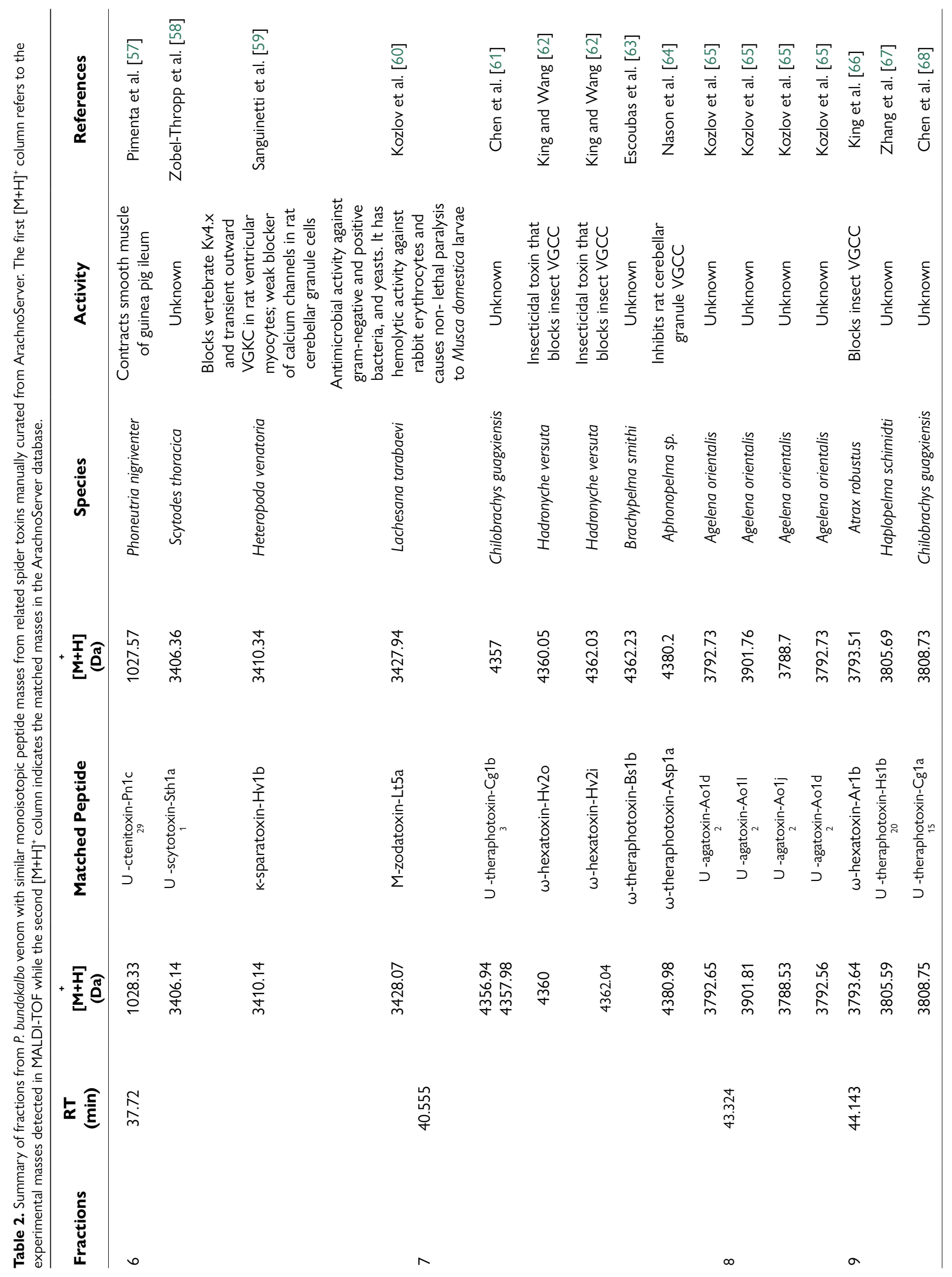




\begin{tabular}{|c|c|c|c|c|c|c|c|c|c|}
\hline 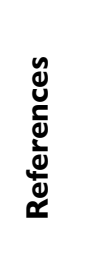 & 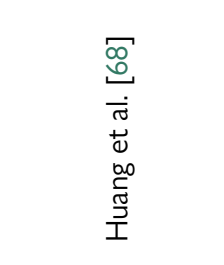 & 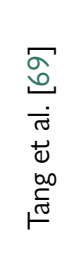 & 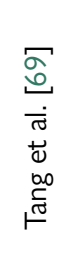 & 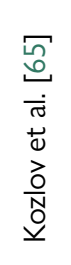 & 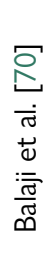 & 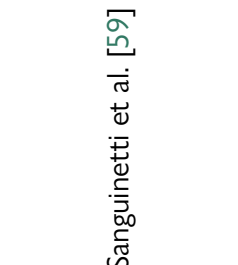 & 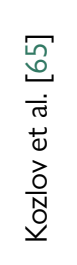 & 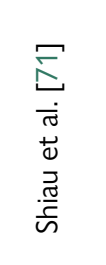 & 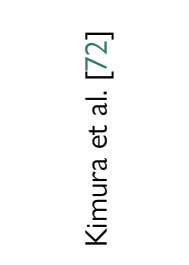 \\
\hline 荎 & 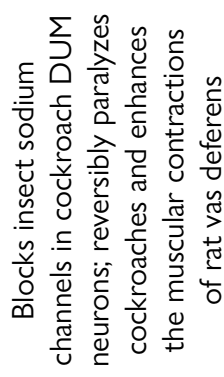 & 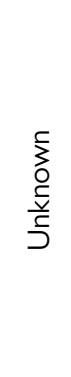 & $\begin{array}{l}\frac{5}{3} \\
\frac{5}{5} \\
\frac{5}{5}\end{array}$ & 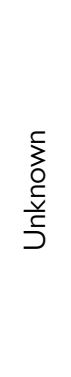 & $\begin{array}{l}\frac{5}{3} \\
0 \\
\frac{5}{5} \\
\text { J }\end{array}$ & 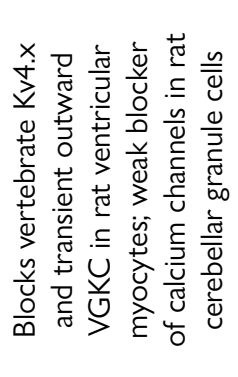 & $\begin{array}{l}\xi \\
\vdots \\
\frac{5}{5} \\
\text { J }\end{array}$ & 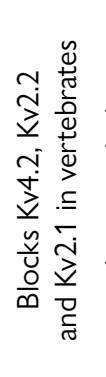 & 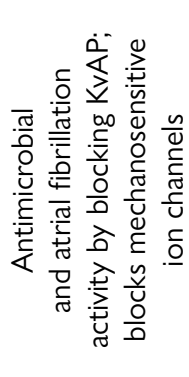 \\
\hline 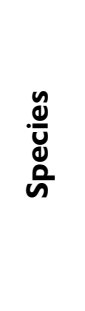 & 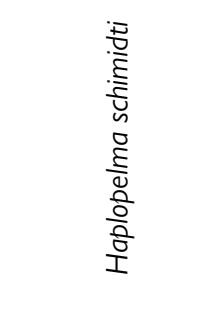 & 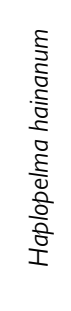 & 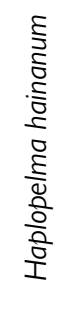 & 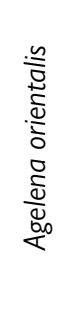 & 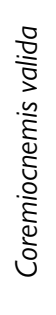 & 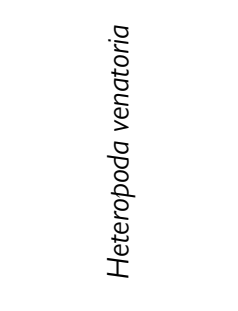 & 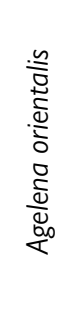 & 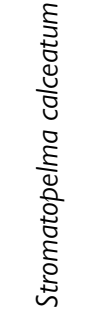 & 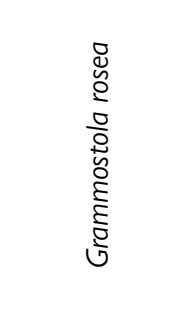 \\
\hline 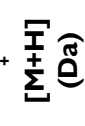 & $\begin{array}{l}\stackrel{0}{0} \\
\stackrel{+}{\circ} \\
\infty \\
m\end{array}$ & 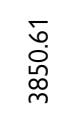 & 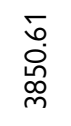 & $\begin{array}{l}\infty \\
\infty \\
\mathbb{i} \\
\infty \\
m\end{array}$ & $\begin{array}{l}\text { m} \\
+\dot{+} \\
\dot{+} \\
\text { mे }\end{array}$ & 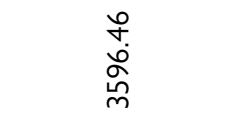 & $\begin{array}{l}\hat{\alpha} \\
\infty \\
\infty \\
\hat{m}\end{array}$ & $\begin{array}{l}n \\
\infty \\
\infty \\
\infty \\
\stackrel{\infty}{m}\end{array}$ & 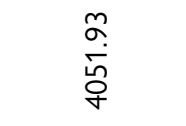 \\
\hline 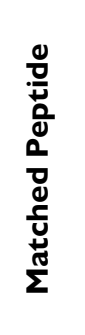 & 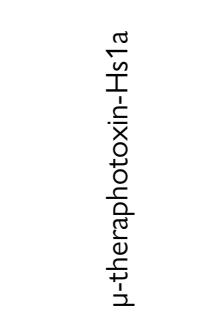 & 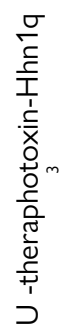 & 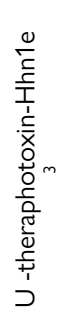 & 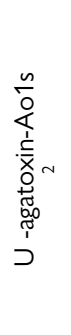 & 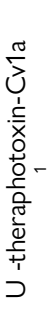 & 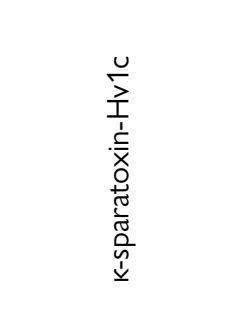 & 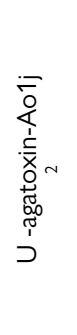 & 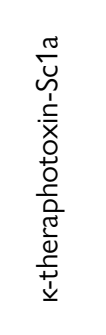 & 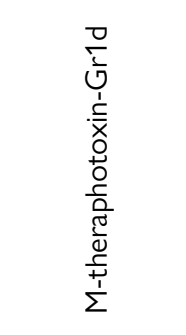 \\
\hline 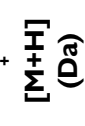 & $\begin{array}{l}\hat{o} \\
\sigma \\
\dot{q} \\
\infty\end{array}$ & 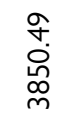 & $\begin{array}{l}\hat{\alpha} \\
\text { ôn } \\
\text { o } \\
\text { m }\end{array}$ & 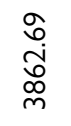 & $\begin{array}{l}\alpha \\
\alpha \\
\dot{0} \\
\text { dे }\end{array}$ & 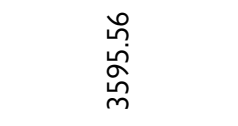 & & $\begin{array}{l}\dot{0} \\
\infty \\
\infty \\
\infty \\
m \\
m\end{array}$ & $\stackrel{\text { ำ }}{\stackrel{n}{\circ}}$ \\
\hline 战 $\widehat{\widehat{\underline{\xi}}}$ & $\begin{array}{l}\alpha \\
0 \\
y \\
y\end{array}$ & & & & $\begin{array}{l}\stackrel{\sigma}{\infty} \\
\stackrel{\alpha}{\sigma} \\
\stackrel{f}{f}\end{array}$ & & I & & \\
\hline$\frac{n}{\tilde{O}}$ & $?$ & & & & $F$ & & 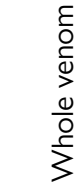 & & \\
\hline
\end{tabular}




\section{Discussion}

Current therapies for treating neurological diseases are ineffective and have side effects associated with their use; therefore, there is a need to develop novel therapies. In this regard, previous studies have shown that neuroactive compounds obtained from the spider venom with neuroprotective effects in vitro and in vivo [73].

\section{P. bundokalbo venom predominantly contains peptidic compounds}

The spider venom constitutes diverse mixture molecules composed of $16 \%$ of small compounds, $11 \%$ of acylpolyamines, $6 \%$ of linear peptides, $60 \%$ cysteine-knotted mini-proteins, $1 \%$ of neurotoxic proteins and $6 \%$ enzymes $[1,63,74-76]$. The components are primarily used for defense against predators and to paralyze their prey for ecological consumption. These toxins which include disulfide-rich peptides, acylpolyamines, and proteins affect the central and peripheral nervous system of their prey by acting on neuronal membrane proteins such as ion channels, receptors, enzymes, and transporters which cumulatively results in disruption of normal neuronal impulse, hence, phenotypically manifests as paralysis on their prey $[1,74]$. On the other hand, the common structural feature of spider venom peptides is cystine-knot mini-proteins. These are members of a large family of small proteins that are defined by a common structural scaffold stabilized by three intramolecular disulfide bonds [75,77]. In addition, they contain a ring formed by disulfide bridges which are the prevailing section of the peptide backbone, with a third disulfide bond penetrating the ring to generate a pseudo-knot. Furthermore, the pseudoknot provides spider venom peptides with exceptional chemical, thermal and biological stability contributing to resistance in extreme $\mathrm{pH}$, organic solvents, high temperatures, and proteases [78]. In addition, prevailing motifs such as inhibitor cystine knots (ICKs) and disulfide-directed beta-hairpin (DDH) motifs are responsible for disulfide bridge formations which are highly evident in tarantula toxins [79]. Moreover, other known PTMs observed in spider venom peptides are $\mathrm{N}$-terminal pyroglutamic acid additional residue, $\mathrm{C}$-terminal amidation, $\mathrm{L}-\mathrm{D}$ isomerization, and palmitoylation could contribute to better structural stability and activity, as well as prevention of exoprotease clevage. Aside from these, other possible PTMs that are present in other animal venoms are $N$ - and $O$ - linked glycosylations, hydroxylations, carboxylations, and bromination of specific amino acids. These types of PTMs alongside structurally related isoforms, variations, and molecular scaffolds, contribute to different mechanisms of pharmacologically based toxin diversifications in spider venom [80-82].

In Phlogiellus bundokalbo venom, the chromatographic profile contains peaks detected at $215 \mathrm{~nm}$ and $280 \mathrm{~nm}$ which generally detect peptides as indicated in Figure 3. Based on the UV spectra library, the wavelength range for the detection of peptide bonds is at $210-220 \mathrm{~nm}$, while for aromatic groups, phenylalanine $(\mathrm{F})$, tyrosine $(\mathrm{Y})$ and tryptophan $(\mathrm{W})$ is detected at $280 \mathrm{~nm}$. Aside from this, the identities of each fraction can be deduced spectrophotometrically wherein the peaks with highest intensity mostly contain peptides and proteins as compared with peaks with lower intensities [83].

In a similar way, analysis of the chromatogram suggests that the compounds present on peaks 1 and 2 are characterized to be polar in nature, peak 3 to 14 to be semi-polar in nature, while peaks 15 and 16 are characterized to be non-polar due to their affinity with the solvent system. Likewise, peaks 2-16 exhibited broad peaks which can be attributed to the solvent conditions established in the RP-HPLC or to the nature of the fractions themselves, which may contain different compounds in a single peak. Moreover, multiple peaks from 5-14 may indicate similar characteristics of each compound present in the chromatogram with respect to their amphiphilicity. The elution of each peak is influence by the nature of the solvent system wherein TFA and $\mathrm{ACN}$ increases the resolution of the peaks in the chromatogram by acting as counter ions to the silanol groups in the stationary phase and increase the hydrophobicity of the mobile phase, respectively, to prevent the adsorption of peptides in the column $[84,85]$.

However, these wavelength ranges are not specific only for peptide bonds and aromatic amino acids as they can be detected for small molecules such as acylpolyamines, organic acids, nucleotides, and free amino acids which are also present in the whole spider venom $[74,83]$. Furthermore, spider venom contains various forms of proteins and enzymes such as phospholipases, hyaluronidases, phosphatases, esterases, and proteases, all of which act as toxins and necrotic factors that are responsible for the damage and lethality at the superficial and deep parts and organs of their predator and prey. Moreover, early eluting peaks or polar compounds in RP-HPLC of various tarantula venoms indicate the characteristic of low molecular weight compounds $(\mathrm{n}<2000 \mathrm{Da})$ such as biogenic amines, polyamines, and small peptides. Also, compounds at $35-55 \%$ of ACN may indicate the presence of peptides with molecular masses at 2000-8000 Da range, while late eluting compounds may represent high molecular weight compounds with masses greater than 10,000 Da [86]. In contrast, MALDI-TOF-MS analysis of $P$. bundokalbo fractions indicates that early eluting fractions, F1 and F2, contain peptidic compounds that are less than $2000 \mathrm{Da}$. Moreover, semipolar eluting fractions, F3 - F14, have peptidic constituents with mass ranges of $2000 \mathrm{Da}-4500 \mathrm{Da}$, and late eluting fractions, F15-F16 contain peptide masses ranging from 1000-2000 Da. These can be attributed to the nature of the sequence, folding, functional groups, and PTMs, which may confer different interactions between constituents in the whole spider venom and their corresponding retention time to the stationary phase [87].

Finally, manual curation of peptides from $P$. bundokalbo in the Arachnoserver, shows that most of the peptide masses from the venom no similarity to the available Phlogiellus sp. toxins in the database. Moreover, it is interesting to note that some of the fractions which demonstrated either anti-AChE or anti-BACE activities have shown similarity of peptide masses to other spider toxins that are related to $P$. bundokalbo by family Theraphosidae and order Araneae suggesting that the peptides from $P$. bundokalbo have not yet recorded in the database [45]. 


\section{BACE proteolytic activity influences loss of activity on $P$. bundokalbo venom peptides in vitro}

BACE is a dimeric and transmembrane aspartic endoprotease localized in the Golgi apparatus of neurons that cleaves several neuronal peptide substrates, including amyloid-precursor protein (APP) [17]. It attaches to the ER and Golgi membrane through its transmembrane and cytoplasmic domain at its C-terminus, which determines its structure, retention, and enzymatic activity [88]. Intrinsic and extrinsic perturbations such as genetic mutations, cellular stress, modifications, inflammation, and other signaling anomalies in neurons contribute to alterations in biosynthesis and activity of BACE, which includes a residue-specific cleavage of APP that leads to the formation of insoluble amyloid-beta $(A \beta)$ or insoluble senile plaques $[17,89]$. The aggregation of insoluble $A \beta$ is one of the main effectors that exacerbates neuronal toxicity, which includes disrupting cellular membranes to form membraneprotein like structures to allow the influx of ions that impair normal cellular processes and initiates mitochondrial oxidative and endoplasmic reticular stress that continually generates toxic proteins and ultimately results to neuronal cell death [13]. Hence, this leads to less neurons transmitting stimuli and responses that phenotypically disrupt cognitive and motor function in patients [90]. Thus, several peptides, antibodies, and small molecule BACE inhibitors were developed primarily from natural products to generate therapeutic leads against BACE [91].

However, most fractional constituents of the spider venom did not exhibit inhibition towards BACE, possibly because the enzyme has numerous peptide substrates where BACE cleavage may occur depending on the degree of activity [47]. Since the spider venom primarily contains peptides as characterized by UV wavelength, colorimetric determination, and MALDI-TOF-MS, cleavage of venom peptides by BACE may result in loss of activity towards its inhibitory activity. Aside from this, BACE is active at acidic $\mathrm{pH}$ ranging from 4.0-5.0, which linearizes and proteolyzes the spider venom peptides by reduction of their distinct PTM, disulfide bridges (S-S) to cysteine (S-H) groups because the - $\mathrm{SH}$ functional side group of cysteine has a pka of 8.8 [92]. Thus, it is hypothesized that pka values lower than 8.8 , such as the case of the acidic $\mathrm{pH}$ environment of BACE, protonates the cystine disulfide bridges of spider venom into cysteine (S-H) allowing BACE proteolytic cleavage which leads to loss of activity of the peptides [92]. Moreover, the regions of the enzyme explained through several works may provide structural insights wherein the venom peptides may contain intrinsic properties towards enzyme activation instead of inhibition [88,93]. Finally, there were no related reports that establish spider venom peptides' intrinsic activity towards BACE inhibition in vitro.

\section{P. bundokalbo venom peptides demonstrates neuroactivity and anti-acetylcholinesterase impact}

AChE (E.C. 3.1.1.7) is a 550 amino acid residue carboxylesterase monomer that hydrolyzes acetylcholine into its choline and acetate derivatives [94]. It localizes in the membrane of the post-synaptic neuron by assembling into tetramers through its tryptophan amphiphilic tetramerization (WAT) domain helices located in the $\mathrm{C}$-terminus region $\mathrm{AChE}$ monomer into the proline-rich attachment domain (PRAD) of the proline-rich membrane anchor (PRIMA) protein to form [ $\left.\mathrm{AChE}_{4}-\mathrm{PRIMA}\right]$ complex [95]. Subsequently, three molecules of [ $\mathrm{AChE}_{4}$-PRIMA] complex attaches to the collagen $\mathrm{Q}$ inside the cell through the cytoplasmic domain of PRIMA protein to "lock" the attached complex and finally form $\left[\mathrm{AChE}_{4}-\mathrm{PRIMA}\right]_{3} \mathrm{COLQ}$ super complex $[96,97]$. The assembly of multiple AChE monomers at the post-synaptic neuron membrane facilitates rapid turnover of acetylcholine after binding and eliciting signals to acetylcholine neurons to regulate the cognitive and motor activities of an individual [94].

However, according to the cholinergic hypothesis in $\mathrm{AD}$, excessive alterations in $\mathrm{AChE}$ alongside reduced cortical innervations, corticocortical glutamatergic neurotransmission, coupling of muscarinic M1 receptors to secondary messengers inside the post-synaptic neuron are contributory factors towards the aggravation of tau protein formation, amyloidogenesis, and amyloidosis which are symptomatic hallmarks of AD [14]. Thus, cholinergic hypothesis provided the foundations for neurotransmitter-based drugs such as acetylcholinesterase inhibitors, most notably, Donepezil. In a neurodegenerative disease-state in patients, the dwindling number of surviving neurons necessitates high amounts of neurotransmitters, in this case, acetylcholine to continue the normal cognitive and motor activities. Therefore, to carry out this event, AChE should be inhibited by donepezil to temporarily increase the number of ACh levels in neurons and facilitate neuronal transmission [18].

Based on the screening results for AChE inhibitory activities, the spider venom generally exhibited weak inhibition in comparison with Donepezil, as indicated in Figure 6. These can be attributed to several factors affecting the weak inhibition of the spider venom in vitro against $\mathrm{AChE}$, which are the diversity of compounds and concentrations of each fraction, the molecular size of the compound present in each fraction, and the nature of the spider venom fractions with respect to their amino acid compositions, functional groups and PTMs towards AChE inhibition.

First, the presence of various compounds in each fraction influences the weak inhibition of AChE which is manifested in the broad and multiple peaks in the chromatogram and the mass distribution profiles in MALDI-TOF-MS. Most notably, this is evident in peaks 6-11 of the chromatogram in Figure 3 of the spider venom, suggesting that there are many compounds present on their similarity in polarity [98]. Another thing to consider is the size and nature of the compounds present in each fraction which affected AChE inhibition in vitro. Since spider venom contains different sizes of post-translationally modified peptides and polypeptides with molecular weight (MW) ranges greater than 2,000 Da, and are more significant than Donepezil, a small molecule with M2 of $379.42 \mathrm{Da}$, it is unlikely that the binding sites for AChE inhibition are the same for the spider 
venom and donepezil, thus, contributing to weak inhibition $[81,82]$. Small molecules can burrow deep into the active site of AChE to exhibit potent inhibition unlike peptides, polypeptides, and mini proteins that can only interact at the periphery of the active or allosteric site on AChE due to their size, thus, may explain the weak inhibition. Likewise, the possible covalent and noncovalent interactions such as disulfide linkages, hydrophobic interactions, van der Waals, London dispersion forces, hydrogen and ionic bonding of spider venom components, and Donepezil via their functional groups to the enzyme are contributory factors to the degree of AChE inhibition [99].

Furthermore, this can be supported by the kinetic inhibition characterization as indicated in Figures 7 and Table 1, which may explain the possible molecular interactions between spider venom peptides, Donepezil, and AChE to exhibit corresponding competitive and uncompetitive inhibitions. First, for competitive inhibitors, which are Donepezil, whole venom, and F3, they bind at the active site of AChE which is the same binding site for ACh for substrate hydrolysis. This could be accredited to the small peptides with MW of less than $2000 \mathrm{Da}$ or molecules present in the whole venom and F3, which manifest weak competitive inhibition compared to Donepezil, which presents strong competitive inhibition in comparison with the untreated $\mathrm{AChE}$ reaction. It can be inferred based on related literatures that the mechanism of inhibition of competitive inhibitors can be attributed to their direct interaction at the catalytic triad, peripheral anionic site, oxyanionic site and choline binding site of AChE to prevent substrate hydrolysis and thereby lower the kinetics of AChE [94]. In addition, it can also be attributed to certain functional groups present especially on the spider venom such as keto groups, carboxyl groups and methoxy groups which interact at the hydroxyl groups of Ser203 in the catalytic triad of AChE to prevent further modification and hydrolysis of ACh $[94,100]$. Furthermore, hydrophobic and positively charged or $\mathrm{N}$-containing functional groups may influence conformational change-induced enzyme inhibition to prevent ACh hydrolysis at the catalytic site of AChE by interaction at specific amino acid residues such as Gly118, Gly119, Ala201 present in the anionic site of the enzyme [94,95]. In the same way, compounds in venom fractions 1 and 16 that exhibited uncompetitive inhibition to AChE-ACh complex in vitro can be attributed to the binding interactions of the compounds at the peripheral anionic sites nearby the choline-binding pocket of the active site, which contains positively charged groups such as amino groups and other N-containing compounds [94]. Aside from this, allosteric inhibition may also be one of the factors for inhibition of AChE because venom peptides may also interact at other sites of AChE, which can induce a conformational change to the structure of AChE and can influence ACh hydrolysis inhibition [94,101]. On the contrary, fractions that show negative inhibition against AChE suggest that they may increase the enzyme activity by interacting in allosteric sites that induce enzyme activation instead of inhibition which may not be ideal if the compounds present in these fractions are developed into AChE inhibitors
$[102,103]$. On the other hand, a study from Undheim et al. [104] that the venom of a related theraphosid spider, Trittame loki, contains $\mathrm{AChE}$ as part of its arsenal. These may also explain the negative inhibition because the additional AChE from $P$. bundokalbo venom may promote ACh catalysis than inhibiting it [104]. Nonetheless, these also suggest that they can be repurposed to other cholinergic-related targets that induce activation or addition of AChE instead of inhibiting it such as in the case of cholinergic poisoning wherein recombinant cholinesterases can be used to rapidly hydrolyze nerve poisons to prevent paralysis in a patient [105].

Aside from this, behavioral results from T. molitor principally contains high levels of neurotransmitters for chemo- and mechanosensory receptors neurons in the peripheral nervous system (PNS) and central nervous system (CNS) of insects. Interestingly, the nervous system of the T. molitor is comprised of several receptors such as acetylcholine, GABA, and glutamate receptors to mediate the regulation of synaptic transmission [74]. Roughly, the nervous system of T. molitor is comparable with that of a human because these insects have functional equivalents of neurotransmitters and neuronal membrane proteins in the body, which are relevant to study for neurodegenerative diseases [106]. Thus, this provides the foundation for T. molitor as an organism to study the neuroactivity effects upon administration of Donepezil and spider venom in vivo. The scoring was based on the rate of motility and convulsive/paralytic-like effects of the venom and Donepezil towards the larvae, wherein 4 is the highest while 1 is the lowest. This is highly attributed to the in vivo action of the venom fractions, whole venom, and Donepezil on T. molitor, wherein spider venom toxins may cause a build-up of neurotransmitters at the synapse which may interact at the pre-synaptic neuronal receptors for a prolonged amount of time in the nervous system of the T. molitor, and phenotypically results to excitations and increase motor activities [50,51,55]. Based on the results from Figure 9, all the mealworms administered with Donepezil whole and selected venom fractions exhibited intense quivering, jerking forward, and backward locomotor activities which can be attributed to excitatory-like effects due to build-up and increased in the concentration of several excitatory neurotransmitters in the synapse of the insect nervous system to transmit elevated neuronal signals in their body. This neuroactivity towards membrane proteins is also shared with other venom toxins from scorpions, snails, snake, and other insects and arthropods which interact with $\mathrm{nAChR}, \mathrm{mAChR}$, adrenergic transporters and receptors, glutamatergic receptors, transient receptor potential (TRP) channels, and voltage-gated sodium, potassium and calcium channels which affect neurotransmitter release, recognition, signaling, and uptake $[41,107,108]$. The results from the behavioral evaluation of T. molitor and AChE inhibition studies suggest that the fractional constituents from P. bundokalbo venom are insightful compounds to focus on cholinergic therapeutics with respect to neurological diseases [109]. Through understanding the complex picture of cholinergic transmission, other receptors, ion channels, and transporters 
(e.g., GABA receptor, glutamate receptors, voltage-gated sodium, potassium, and calcium channels, and acetylcholine transporters) are also involved in delivering neuronal information which could also be affected in neurodegenerative disease state as demonstrated by cholinergic hypothesis in AD $[12,14,15,110]$. However, since the etiology of neurodegenerative diseases are multifactorial that mainly involves signaling through membrane proteins and the pharmacological activities of the spider venom compounds that target membrane proteins, this shows that they can also be studied to modulate other membrane proteins, aside from AChE, with the focus on discovery and development of cholinergic-related compounds.

\section{Conclusion}

In this preliminary study, the $P$. bundokalbo spider venom fractions from Mindanao, Philippines, contain compounds that showed notable behavioral activities in vivo and $\mathrm{AChE}$ inhibitory activities but not in BACE in vitro. Hence, further research on $P$. bundokalbo venom should focus on developing it for cholinergic studies such as investigating cholinergicrelated membrane proteins (e.g., ion channels, receptors, and transporters) aside from $\mathrm{AChE}$ that contributes towards plaque and tangle degradation, modulation of neuroinflammation, and neuroprotective effects against Alzheimer's disease and other neurological diseases. Similarly, dose-dependent evaluation, purification, identification, and structural elucidation of putative cholinergic compounds from the spider venom are essential to developing into its more potent, stable, and target-specific forms against neurodegenerative diseases.

\section{Acknowledgments}

The authors would like to thank the local government of Bagacay, Siargao, Mindanao and the Provincial Environment and Natural Resources Office for the permission for collecting spiders (Resolution no. 2018-27). Furthermore, the authors would like to thank the collaborators from the Mindanao State University-Iligan Institute of Technology (MSU-IIT) lead by Dr. Olga Nuñeza for collecting spiders and the Museum of Natural History of the University of the Philippines Los Baños (MNHUPLB) lead by Dr. Alberto T. Barrion and Dr. Aimee Lynn A. Barrion-Dupo for spider identification and authentication. The group would also like to thank Mr. Reymart R. Choa for the images of the animals.

\section{Availability of data and materials}

The datasets generated and analyzed in this study are available from the first author and corresponding author on reasonable request. Samples of spiders are deposited in Mindanao State University-Iligan Institute of Technology for further taxonomic study.

\section{Funding}

The present work was partially funded by the Commission on Higher Education (CHED), Research and Development and Extension, though RDE-GIA (Resolution no. 972-2016) research program entitled "Screening and Characterization of Peptides with In Vitro Bioactivity from Venoms Isolated from Theraphosidae and Lycosidae of Philippine Spiders for Therapeutic Leads". The National Research Council of the Philippines also financially supported this publication. In addition, the Shimadzu Axima Confidence Linear/Reflectron MALDI-TOF-MS system was acquired through CHED Philippine-California Advanced Research Institutes - Institute for Health Innovation and Translational Medicine Project 63 (PCARI-IHITM 63).

\section{Competing interests}

The authors declare that they have no competing interests.

\section{Authors' contributions}

SMML, JSA, JBBF, AGJL, MRRE, and MKPD designed and performed the enzymatic and worm experiments, analyzed and interpreted the data, and wrote the paper and participated in the revisions of it. They were supervised by LAS that conceived the research and participated in the revision of the manuscript. LAG conducted the venom extraction, optimization of RP-HPLC conditions and helped in the interpretation of the results and revision of the manuscript. CMVR performed MALDI-TOFMS on spider venom fractions which was supervised by AJLV. SMML and MRSB helped in the mass analysis of peptides in samples as well as participated in the revision of the manuscript. MRSB is the principal investigator of the CHED RDE-GIA program, "Screening and Characterization of Peptides with In vitro Bioactivity from Venoms Isolated from Theraphosidae and Lycosidae of Philippine Spiders for Therapeutic Leads" from where the some of the funds of this research was obtained. She also helped in the revision of the manuscript. All authors read and approved the final manuscript

\section{Ethics approval}

Not Applicable.

\section{Consent for publication}

Not applicable.

\section{References}

1. King GF, Hardy MC. Spider-venom peptides: structure, pharmacology, and potential for control of insect pests. Annu Rev Entomol. 2013;58:475-496. doi: 10.1146/annurev-ento-120811-153650.

2. Napolitano T, Holford M. Breakthroughs in venom peptide screening methods to advance future drug discovery. Protein Peptide Lett. 2018;25(12):1137-48. doi: 10.2174/0929866525666181101103047. 
3. Fratini F, Cilia G, Turchi B, Felicioli A. Insects, arachnids and centipedes venom: a powerful weapon against bacteria. a literature review. Toxicon. 2017;130:91-103. doi: 10.1016/j.toxicon.2017.02.020.

4. Prommer E. Ziconitide: a new option for refractory pain. Drugs Today (Barc). 2006;42(6):369. doi: 10.1358/dot.2006.42.6.973534

5. Brookes ME, Eldabe S, Batterham A. Ziconitide monotherapy: a systematic review of randomised controlled trials. Curr Neurophamacol. 2017;15(2). doi: $10.2174 / 1570159 \times 14666160210142056$.

6. Abbade LPF, Ferreira Jr RS, Santos LD, Barraviera B. Chronic venous ulcers: a review on treatment with fibrin sealant and prognostic advances using proteomic strategis. J Venom Anim Toxins Incl Trop Dis. 2020;26:e20190101. doi: 10.1590/1678-9199-jvatitd-2019-0101.

7. Abbade LPF, Barraviera SRSCS, Silvares MRC, Lima ABBDCL, Haddad GRR, Gatti MAN, Medolago, NB, Rigotto CMT, dos Santos LD, Ferreira RS, Barraviera B. Treatment of chronic venous ulcers with heterologous fibrin sealant: a phase I/II clinical trial. Front Immunol. 2021 Feb 23;12:627541. doi: 10.3389/fimmu.2021.627541.

8. Barbosa AN, Boyer L, Chippaux JP, Medolago NB, Caramori CA, Paixão AG, Poli JPV, Mendes MB, Dos Santos LD, Ferreira Jr RS, Barraviera B. A clinical trial protocol to treat massive Africanized honeybee (Apis mellifera) attach with a new apilic antivenom. J Venom Anim Toxins Incl Trop Dis. 2017;23:14. doi: 10.1186/s40409-017-0106-y

9. Barbosa AN, Ferreira Jr RS, de Carvalho FCT, Schuelter-Trevisol F, Mendes M, Mendonça, Batista JN, Trevisol DJ, Boyer L, Chippaux JP, Medolago NB, Cassaro CV, Carneiro MTR, de Oliveira APP, Pimenta DC, da Cunha LER, dos Santos LD, Barraviera B. Single-arm, multicenter phase $\mathrm{i} / \mathrm{ii}$ clinical trial for the treatment of envenomings by massive africanized honey bee stings using the unique apilic venom. Front Immunol. 2021 Mar 23;12:653151. doi: 10.3389/fimmu.2021.653151.

10. World Health Organization [Internet]. Dementia [cited 2020 Nov 4]. Available from: https://www.who.int/news-room/fact-sheets/detail/ dementia.

11. Dominguez J, de Guzman MF, Reandelar M, Phung TKT. Prevalence of dementia and associated risk factors: a population-based study in the philippines. J Alzheimers Dis. 2018;63(3):1065-1073. doi: 10.3233/ JAD-180095.

12. Zhang $P, X u S$, Zhu Z, Xu J. Multi-target design strategies for the improved treatment of Alzheimer's disease. Eur J Med Chem. 2019;176:228-47. doi: 10.1016/j.ejmech.2019.05.020.

13. Gan L, Cookson MR, Petrucelli L, La Spada AR. Converging pathways in neurodegeneration, from genetics to mechanisms. Nat Neurosci. 2018;21(10):1300-09. doi: 10.1038/s41593-018-0237-7.

14. Francis PT, Palmer AM, Snape M, Wilcock GK. The cholinergic hypothesis in Alzheimer's disease: a review of progress. J Neurol Neurosurg Psychiatry. 1999 Feb;66(2):137-47. doi: 10.1136/jnnp.66.2.137.

15. Fisher A. Cholinergic modulation of amyloid precursor protein processing with emphasis on $\mathrm{m} 1$ muscarinic receptor: perspectives and challenges in treatment of Alzheimer's disease. J Neurochem. 2011;120:22-33. doi: 10.1111/j.1471-4159.2011.07507.x.

16. Fabiani C, Antollini SS. Alzheimer's disease as a membrane disorder: spatial cross-talk among beta-amyloid peptides, nicotinic acetylcholine receptors and lipid rafts. Front Cell Neurosci. 2019;13(309):1-28. doi: 10.3389/fncel.2019.00309.

17. Müller UC, Deller T, Korte M. Not just amyloid: physiological functions of the amyloid precursor protein family. Nat Rev Neurosci. 2017;18(5):28198. doi: 10.1038/nrn.2017.29.

18. Stahl SM. The new cholinesterase inhibitors for Alzheimer's disease, part 2: illustrating their mechanisms of action. J Clin Psychiatry. 2000;61(11):813814. doi: 10.4088/jcp.v61n1101.

19. Rombouts F, Kusakabe K, Hsiao C, Gijsen HJM. Small-molecule BACE1 inhibitors: a patent literature review (2011 to 2020). Expert Opin Ther Pat. 2021 Jan;31(1):25-52. doi: 10.1080/13543776.2021.1832463.

20. Hogan DB. Long-term efficacy and toxicity of cholinesterase inhibitors in the treatment of Alzheimer disease. Can J Psychiatry. 2014;59(12):618-23. doi: $10.1177 / 070674371405901202$.
21. Panza F, Lozupone $M$, Watling $M$, Imbimbo BP. Do BACE inhibitor failures in Alzheimer patients challenge the amyloid hypothesis of the disease? Expert Rev Neurother. 2019;19(7):599-602. doi: 10.1080/14737175.2019.1621751.

22. Cummings J, Aisen PS, DuBois B, Frölich L, Jack Jr CR, Wones RW, Morris JC, Dowsett SA, Scheltens P. Drug development in Alzheimer's disease: the path to 2025. Alzheimers Res Ther. 2016 Sep 20;8:39. doi: 10.1186/s13195-016-0207-9.

23. Danysz W, Parsons CG. Alzheimer's disease, $\beta$-amyloid, glutamate, NMDA receptors and memantine- searching for the connections. $\mathrm{Br}$ J Pharmacol. 2012;167(2):324-52. doi: 10.1111/j.1476-5381.2012.02057.x.

24. Thei L, Imm J, Kaisis E, Dallas ML, Kerrigan TL. Microglia in Alzheimer's disease: a role for ion channels. Front Neurosci. 2018;12(676):1-23. doi: 10.3389/fnins.2018.00676.

25. Yang $X$, Wang $Y$, Wu C, Ling E. Animal venom peptides as a treasure trove for new therapeutics against neurodegenerative disorders. Curr Med Chem. 2019;26(25):4749-74. doi: 10.2174/0929867325666181031122438.

26. Juario JV, Nuñeza OM, Dupo ALB. Species richness of spiders in Sacred Mountain, Marawi city, Philippines. J Biodivers Environ Sci. 2016;8(1):86-94.

27. Quiñones LE, Barrion-Dupo ALA, Nuñeza OM. Species richness of orb web spiders (Araneae: Araneidae) in Rajah Sikatuna Protected Landscape (RSPL), Bohol, Philippines. J Biodiver Environ Sci. 2016;8(5):136-46.

28. Lalisan JA, Dupo ALB, Nuneza OM. Diversity of spiders along an elevational gradient in Mt. Pinukis, Zamboanga del Sur, Philippines. J Biodiver Environ Sci. 2017;7(5):190-201.

29. Dacanay CC, Dupo AL, Nuneza OM. Rapid assessment of spider fauna of Pulacan Falls, Zamboanga Del Sur, Philippines. J Biodiver Environ Sci. 2014;5(1):2222-3045.

30. Chua JC, Uba MO, Carvaja TM. A rapid assessment of spider diversity in Kabigan Falls, Pagudpud, llocos Norte, Philippines. Phil J Syst Biol. 2014; 8:17-25.

31. Barrion AT, Litsinger JA. Riceland spiders of south and southeast Asia. Wallingford, UK: CAB International; 1995.

32. Barrion-Dupo ALA, Barrion AT, Rasalan JB. A new cave-dwelling mygalomorph spider of the genus Phlogiellus Pocock, 1897 (Araneae: Theraphosidae: Selenocosmiinae) from Burdeos, Polillo Island, Quezon Province, Philippines. Phil J Syst Biol. 2014;8:1-15.

33. Rasalan JB, Barrion-Dupo ALA, Bicaldo PRD, Sotto MP. Spider assemblages of Putting Bato Cave 3-4 and surrounding Karst Forest environs, with additional notes on the cave-dwelling nature of Phlogiellus kwebaburdeos. Mus Pub Nat His. 2015;4:18-25.

34. Nunn SC, West RC, Wirth VV. A revision of the Selinocosmiin tarantula genus Phlogiellus Pocock 1897 (Araneae: Theraphosidae) with description of 4 new species. Int J Zool. 2016;1-54. doi: 10.1155/2016/9895234.

35. Lopez SMM, Aguilar JS, Fernandez JBB, Lao AGJ, Estrella MRR, Devanadera MKP, Mayor ABR, Guevarra LA, Santiago-Bautista MR, Santiago LA. The venom of Philippine tarantula (Theraphosdae) contains peptides with prooxidative and nitrosative-dependent cytotoxic activities against breast cancer cells (MCF-7) in vitro. Asian Pac J Cancer Prev. 2020;21(8):2423-30. doi: 10.31557/APJCP.2020.21.8.2423.

36. Mayor ABR, Guevarra LA, Santiago-Bautista MR, Santiago LA. Phlogiellus bundokalbo spider venom: cytotoxic fractions against human lung adenocarcinoma (A549) cells. J Venom Anim Toxins Incl Trop Dis. 2020;26:e20190104. doi: 10.1590/1678-9199-jvatitd-2019-0104.

37. Santiago-Bautista MR, Petros GDT, Lopez SMM, Nuneza OM, Guevarra JR L, Santiago LA. Phlogiellus bundokalbo spider venom: Its neuroactive, phospholipase a2 and cytotoxic components against human breast adenocarcinoma (MCF-7). Phil J Health Res Dev. 2021;25(1):36-48.

38. Gomes GM, Dalmolin GD, Cordeiro MdN, Gomez MV, Ferreira J, Rubin MA. The selective A-type $\mathrm{K}+$ current blocker Tx3-1 isolated from the Phoneutria nigriventer venom enhances memory of naïve and $A \beta(25-35)$ treated mice. Toxicon. 2013;76:23-7. doi: 10.1016/j.toxicon.2013.08.059.

39. Silva FR, Batista EM, Gomez MV, Kushmerick C, Da Silva JF, Cordiero MN, Vieira LB, Ribeiro FM. The Phoneutria nigriventer spider toxin, PnTx45-5, promotes neuronal survival by blocking NMDA receptors. Toxicon. 2016;112:16-21. doi: 10.1016/j.toxicon.2016.01.056. 
40. de Souza JM, Goncalves BDC, Gomez MV, Vieira LB, Ribeiro FM. Animal toxins as therapeutic tools to treat neurodegenerative diseases. Front Pharmacol. 2018;9(145):1-25. doi: 10.3389/fphar.2018.00145.

41. Rigo FK, Rossato M F, Trevisan G, Dal-Toé De Prá S, Ineu RP, Duarte MB, de Castro Jr C], Ferreira J, Gomez MV. PhKv, a toxin Isolated from the Spider venom induces antinociception by inhibition of cholinesterase activating cholinergic system. Scand J Pain. 2017;17:203-210. doi: 10.1016/j. sjpain.2017.09.022.

42. Chassognon IR, McCarthy CA, Chin YK, Pineda SS, Keramdas A, Mobli M, Vi P, De Silva TM, Lynch JW, Widdop RE, Rash LD, King GF. Potent neuroprotection after stroke afforded by a double-knot spider-venom peptide that inhibits acid-sensing ion channel 1a. PNAS. 2017;114(14):37505. doi: 10.1073/pnas.1614728114.

43. Estrada-Gomez S, Muñoz LJV, Lanchero P, Latorre CS. Partial characterization of venom from the Colombian spider Phoneutria boliviensis (Aranae:Ctenidae). Toxins. 2015;7(8):2872-87. doi: 10.3390/ toxins7082872.

44. He F. BCA (Bicinchoninic acid) protein assay. Bio-101: e44. DOI: 10.21769/ BioProtoc. 44

45. Pineda SS, Chaumeil PA, Kunert A, Kaas Q, Thang MWC, Le L, Nuhn M, Herzig V, Saez NJ, Cristofori-Armstrong B, Anangi R, Senff S, Gorse D, King GF. ArachnoServer 3.0: An online server for automated discovery, analysis and annotation of spider toxins. Bioinformatics. 2018;34(6):10746. doi: 10.1093/bioinformatics/bt×661.

46. Je JY, Kim SK. Water-soluble chitosan derivatives as a BACE1 inhibitor. Bioorg Med Chem. 2005;13(23):6551-5. doi: 10.1016/j.bmc.2005.07.004.

47. Ermolieff J,Loy JA, Koelsch G, Tang J. Proteolytic activation of recombinant pro-memapsin 2 (Pro- $\beta$-secretase) studied with new fluoregenic substrates. Biochem. 2000;39(40):12450-6. doi: 10.1021/bi001494f.

48. Ellman GL, Courtney KD, Andres V, Featherstone RM. A new and rapid colorimetric determination of acetylcholinesterase activity. Biochem Pharmacol. 1961;7(2):88-95. doi: 10.1016/0006-2952(61)90145-9.

49. Santiago LA, Pineda PJO, Gerona MLG. Preliminary study on the acetylcholinesterase inhibitory activity of Ipomoea muricata (Linnaeus) Jacquin. Int J Pharm Sci Res. 2016;7(1):108-14. doi: 10.13040/ IJPSR.0975-8232.7(1).

50. Friedel T, Nentwig W. Immobilizing and lethal effects of spider venoms on the cockroach and the common mealbeetle. Toxicon. 1989;27(3):305-16. doi:10.1016/0041-0101(89)90178-5.

51. Hardy MC, Daly NL, Mobli M, Morales RAV, King GF. Isolation of an orally active insecticidal toxin from the venom of an australian tarantula. Plos One. 2013;8(9):1-12. doi: 10.1371/journal.pone.0073136.

52. Berg JM, Tymoczko JL, Stryer L. Biochemistry (5th ed.). New York: W. H. Freeman and Co; 2002.

53. Smolira A, Wessely-Szponder. Importance of the matrix and the matrix/ sample ratio in MALDI-TOF-MS analysis of cathelicidins obtained from porcine neutrophils. Appl Biochem Biotechnol. 2015;175:2050-65. doi: 10.1007/s12010-014-1405-1.

54. Escoubas P, Sollod B, King GF. Venom landscapes: mining the complexity of spider venoms via a combined cDNA and mass spectrometric approach. Toxicon. 2006;47(6):650-63. doi: 10.1016/j.toxicon.2006.01.018.

55. [55] Masuoka T, Uwada J, Kudo M, Yoshiki H, Yamashita Y, Taniguchi T, Nishio M, Ishibashi T, Muramatsu I. Augmentation of endogenous acetylcholine uptake and cholinergic facilitation of hippocampal long-term potentiation by acetylcholinesterase inhibition. Neurosci. 2019;404:39-47. doi: 10.1016/j.neuroscience.2019.01.042.

56. Gonçalves TC, Lesport P, Kuylle S, Stura E, Ciolek J, Mourier G, Servent D, Bourinet E, Benoit E, Gilles N. Evaluation of the spider (Phlogiellus genus) phlotoxin 1 and synthetic variants as antinociceptive drug candidates. Toxins. 2019:11(484):2-18. doi: 10.3390/toxins11090484.

57. Pimenta AMC, Rates B, Bloch Jr C, Gomes PC, Santoro MM, de Lima ME, Richardson Corderio, MdN. Electrospray ionization quadrupole time-of-flight and matrix-assisted laser desorption/ionization tandem time-of-flight mass spectrometric analyses to solve micro-heterogeneity in post-translationally modified peptides from Phoneutria nigriventer (Aranea, Ctenidae) venom. Rapid Commun in Mass Spectrom. 2005;19(1):31-7. doi: $10.1002 / \mathrm{rcm} .1751$.
58. Zobel-Thropp PA, Correa SM, Garb JE, Binford GJ. Spit and venom from scytodes spiders: a diverse and distinct cocktail. J Proteome Res. 2014;13(2):817-35. doi:10.1021/pr400875s.

59. Sanguinetti MC, Johnson JH, Hammerland LG, Kelbaugh PR, Volkmann RA, Saccomano NA, Mueller AL. Heteropadatoxins: peptides isolated from spider venom that block Kv4.2 potassium channels. Mol Pharmacol. 1997;51(3):491-8.

60. Kozlov SA, Vassilevski AA, Feofanov AV, Surovoy AY, Karpunin DV, Grishin EV. Latarcins, antimicrobial and cytolytic peptides from the venom of the spider Lachesana tarabaevi (Zodariidae) that exemplify biomolecular diversity. J Biol Chem. 2006;281(30):20983-92. doi:10.1074/ jbc.M602168200.

61. Chen J, Deng M, He Q, Meng E, Jiang L, Liao Z, Rong M, Liang S. Molecular diversity and evolution of cystine knot toxins of the tarantula Chilobrachys jingzhao. Cell Mol Life Sci. 2008;65(15):2431-44. doi: 10.1007/s00018008-8135-x.

62. King GF, Wang $X$, inventors; University of Connecticut, applicant. Insecticidal compounds and methods for selection thereof. Australia patent AU2001238152. May 10, 2011.

63. Escoubas $P$, Célérier $M$, Nakajima T. High-performance liquid chromatography matrix-assisted laser desorption/ionization time-offlight mass spectrometry peptide fingerprinting of tarantula venoms in the genus Brachypelma: chemotaxonomic and biochemical applications. Rapid Commun Mass Spectrom. 1997;11(17):1891-9. doi: 10.1002/(SICI)10970231(199711)11:17<1891::AID-RCM94>3.0.CO;2-X.

64. Nason DM, Phillips D, Saccomano NA, Volkmann RA, inventors; Pfizer Inc., NPS Pharmaceuticals Inc., applicants. Calcium channel blocking polypeptides from Theraphosidae Aphonopelma. International patent WO 94/10196. May 11, 1994. Available from: https://patentimages.storage. googleapis.com/30/b7/58/042d09da06b2d6/WO1994010196A1.pdf.

65. Kozlov S, Malyabka A, McCutchen B, Lu A, Schepers E, Herrmann R, Grishin E. A novel strategy for the identification of toxinlike structures in spider venom. Proteins. 2005;59(1):131-40. doi:10.1002/prot.20390.

66. King GF, Mukherjee AK, Wikel SK, McFarland BS, inventors. University of Connecticut, assignee. Acaricidal compostions and methods of use therof. United States patent US7,575,758B2. August 18, 2009. Available from: https://patentimages.storage.googleapis.com/d3/dc/16/1cd5c910cbb80f/ US7575758.pdf.

67. Zhang Y, Huang Y, He, Q, Liu J, Luo J, Zhu L, Lu S, Huang P, Chen X, Zeng X, Liang S. Toxin diversity revealed by a transcriptomic study of Ornithoctonus huwena. PloS ONE. 2014;9(6). doi:10.1371/journal.pone.0100682.

68. Huang RH, Liu ZH, Liang SP. Purification and characterization of a neurotoxic peptide huxentoxin-III and a natural inactive mutant from the veom of the spider Selenocosmia huwena Wang (Ornithoctonus huwena Wang). Sheng Wu Hua Xue Yu Sheng Wu Wu Li Xue Bao (Shanghai). 2003 Nov;35(11):976-80.

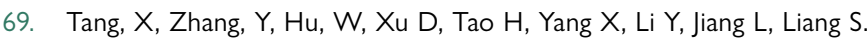
Molecular diversification of peptide toxins from the tarantula Haplopelma hainanum (Ornithoctonus hainana) venom based on transcriptomic, peptidomic, and genomic analyses. J Proteomeo Res. 2010;9(5):255064. doi: 10.1021/pr1000016.

70. Balaji RA, Sasaki T, Gopalakrishnakone P, Sato K, Kini RM, Bay BH. Purification, structure determination and synthesis of covalitoxin-II, a short insect-specific neurotoxic peptide from the venom of Coremiocnemis Validus (Singapore tarantula). FEBS Lett. 2000;474(2-3):208-12. doi: 10.1016/s0014- 5793(00)01593-3.

71. Shiau YS, Huang PT, Liou HH, Liaw YC, Shiau YY, Lou KL. Structural basis of binding and inhibition of novel tarantula toxins in mammalian voltage-dependent potassium channels. Chem Res Toxicol. 2003;16(10): 1217-25. doi: 10.1021/t×0341097.

72. Kimura T, Ono S, Kubo T. Molecular cloning and sequence analysis of the cDNAs encoding toxin like peptides from the venom glands of tarantula Grammostola rosea. Int J Peptides. 2012;1-12. doi: 10.1155/2012/731293.

73. Primini EO, Liberato JL, Fontana ACK, Dos Santos WF. Neuroprotective properties of RT10, a fraction isolated from Parawixia bistrata spider venom, against excitatory injury in neuron-glia cultures. J Venom Anim Toxins Incl Trop Dis. 2019;25:e148818. doi: 10.1590/1678-9199-JVATITD-1488-18. 
74. Kuhn-Nentwig L, Stöcklin R, Nentwig W. Venom composition and strategies in spiders: is everything possible? Adv In Insect Phys. 2011;40:186. doi: 10.1016/B978-0-12-387668-3.00001-5.

75. Mourão CBF, Oliveira FN, Carvalho, Arenas CJ, Duque HM, Gonçalves JC, Macêdo JKA, Galante P, Schwartz CA, Mortari MR, Santos MDFMA, Schwartz EF. Venomic and pharmacological activity of Acanthoscurria paulensis (Theraphosidae) spider venom. Toxicon. 2013;61:129-38. doi: 10.1016/j.toxicon.2012.11.008.

76. Langenegger N, Nentwig W, Kuhn-Nentwig L. Spider venom: components, modes of action, and novel strategies in transcriptomic and proteomic analyses. Toxins. 2019;11(10):1-44. doi: 10.3390/toxins11100611.

77. Dongol Y, Cardoso FC, Lewis RJ. Spider knottin pharmacology at voltagegated sodium channels and their potential to modulate pain pathways. Toxins. 2019;11(626):1-39. doi: 10.3390/toxins11110626.

78. Kolmar H. Alternative binding proteins: biological activity and therapeutic potential of cystine-knot miniproteins. FEBS J. 2008;275(11):2684-90. doi: 10.1111/j.1742-4658.2008.06440.x.

79. Herzig V, King GF. The neurotoxic mode of action of venoms from the spider family Theraphosidae. Spider Ecophysiol. 2012;203-15. doi:10.1007/978-3-642-33989-9_15.

80. Diego-García E, Peigneur S, Waelkens E, Debaveye S, Tytgat J. Venom components from Citharischius crawshayi spider (family Theraphosidae): exploring transcriptome, venomics, and function. Cell Mol Life Sci. 2010;67(16):2799-813. doi: 10.1007/s00018-010-0359-x.

81. Escoubas P, Quinton L, Nicholson GM. Venomics: unravelling the complexity of animal venoms with mass spectrometry. J Mass Spectrom. 2008;43(3):279-295. doi: 10.1002/jms.

82. Escoubas P. Molecular diversification in spider venoms: a web of combinatorial peptide libraries. Mol Divers. 2006;10:545-54. doi: 10.1007/ s11030-006-9050-4.

83. Spinelli S, Gonzalez C, Thomas O. Chapter 11 UV spectra library. Tech Instrum Anal Chem. 2007;27:267-356. doi: 10.1016/S0167-9244(07)80013-8.

84. Bennett HPJ, Browne CA, Solomon S. The use of perfluorinated carboxylic acids in the reversed-phase HPLC of peptides. J Liq Chromatogr. 1980;3(9):1353-65. doi: 10.1080/01483918008062781.

85. Åsberg D, Langborg Weinmann A, Leek T, Lewis RJ, Klarqvist M, Leśko M, Kaczmarski K, Samuelsson J, Fornstedt T. The importance of ionpairing in peptide purification by reversed-phase liquid chromatography. J Chromatogr A. 2017;1496:80-91. doi: 10.1016/j.chroma.2017.03.041.

86. Schmidt J. Arthropod toxins and venoms. In: Mullen GR, Lance AD. Medical and veterinary entomology. 3rd ed. London: Academic Press, 2019. doi: 10.1016/B978-0-12-814043-7.00003-0.

87. Hu Z, Zhou X, Chen J, Tang C, Xiao Z, Ying D, Liu Z, Liang S. The venom of the spider Selenocosmia jiafu contains various neurotoxins acting on voltage-gated ion channels in rat dorsal root ganglion neurons. Toxins. 2014;6(3):988-1001. doi: 10.3390/toxins6030988.

88. Wang H, Li R, Shen Y. $\beta$-Secretase: its biology as a therapeutic target in diseases. Trends Pharmacol Sci. 2013;34(4):215-25. doi: 10.1016/j. tips.2013.01.008.

89. De Strooper B, Vassar R, Golde T. The secretases: enzymes with therapeutic potential in Alzheimer disease. Nat Rev Neurol. 2010;6:99107. doi: $10.1038 /$ nrneurol.2009.218.

90. Styr B, Slutsky I. Imbalance between firing homeostasis and synaptic plasticity drives early phase Alzheimer's disease. Nat Neurosci. 2018;21:463-73. doi: 10.1038/s41593-018-0080-x.

91. Vassar R. $\beta$-Secretase inhibition. In: Wolfe MS. Developing Therapeutics for Alzheimer's Disease: Progress and Challenges. London: Academic Press; 2016. pp. 39-62. doi:10.1016/b978-0-12-802173-6.00003-4.

92. Albert A, Eksteen J, Isaksson J, Sengee M, Hansen T, Vasskog T. General approach to determine disulfide connectivity in cysteine-rich peptides by sequential alkylation on solid phase and mass spectrometry. Anal Chem. 2016;88(19):9539-46. doi: 10.1021/acs.analchem.6b02115.
93. Gutiérrez LJ, Andujar SA, Enriz RD, Baldoni HA. Structural and functional insights into the anti-BACE1 Fab fragment that recognizes the BACE1 exosite. J Biomol Struct Dyn. 2013;32(9):1421-33. doi:10.1080/073911 02.2013.821024.

94. Colovic MB, Krstic DZ, Lazarevic-Pasti TD, Bondzic AM, Vasic VM. Acetylcholinesterase inhibitors: pharmacology and toxicology. Curr Neuropharmacol. 2013;11(3):315-35. doi: 10.2174/1570159X11311030006.

95. Perrier AL, Massoulié J, Krejci E. PRiMA: the membrane anchor of acetylcholinesterase in the brain. Neuron. 2002;33(2):275-85. doi: 10.1016/ S0896-6273(01)00584-0.

96. Simon S, Krejci E, Massoulié J. A four-to-one association between peptide motifs: four C-terminal domains from cholinesterase assemble with one proline-rich attachment domain (PRAD) in the secretory pathway. EMBO J. 1998;17(21):6178-87. doi: 10.1093/emboj/17.21.6178.

97. Dvir H, Harel M, Bon S, Liu W, Vidal M, Garbay C, Sussman JL, Massoulie J, Silman I. The synaptic acetylcholinesterase tetramer assembles around a polyproline II helix. EMBO J. 2004;23(22):4394-405. doi: 10.1038/ sj.emboj.7600425.

98. Kuhn-Nentwig L, Schaller J, Nentwig W. Biochemistry, toxicology and ecology of the venom of the spider Cupiennius salei (Ctenidae). Toxicon. 2004;43(5):543-53. doi: 10.1016/j.toxicon.2004.02.009.

99. Ordentlich A, Barak D, Kronman C, Ariel N, Segall Y, Velan B, Shafferman A. The architecture of human acetylcholinesterase active center probed by interactions with selected organophosphate inhibitors. J Biol Chem. 1996;271(20):11953-62. doi: 10.1074/jbc.271.20.11953.

100. Soreq H, Seidman S. Acetylcholinesterase - new roles for an old actor. Nat Rev Neurosci. 2001;2(4):294-302. doi: 10.1038/35067589.

101. Roca C, Requena C, Sebastian-Perez V, Malhotra S, Radoux C, Perez C, Martinez A, Paez JA, Blundell TL, Campillo NE. Identification of new allosteric sites and modulators of AChE through computational and experimental tools. J Enzyme Inhib Med Chem. 2018;33(1):1034-47. doi: 10.1080/14756366.2018.1476502.

102. Radić Z, Quinn DM, Vellom DC, Camp S, Taylor P. Allosteric control of acetylcholinesterase catalysis by fasciculin. J Biol Chem. 1995;270(85):203919. doi: 10.1074/jbc.270.35.20391.

103. Rosenberry TL, Johnson JL, Cusack B, Thomas JL, Emani S, Venkatasubban KS. Interactions between the peripheral site and the acylation site in acetylcholinesterase. Chem Biol Interact. 2005;157-58:181-9. doi: 10.1016/j. cbi.2005.10.027.

104. Undheim EAB, Sunagar K, Herzig V, Kely L, Low DHW, Jackson TNW, Jones A, Kurniawan N, King GF, Ali SA, Antunes A, Ruder T, Fry BG. A proteomics and transcriptomics investigation of the venom from the barychelid spider Trittameloki (brush-foot trapdoor). Toxins. 2013;5(12):2488-503. doi: 10.3390/toxins5122488.

105. Kronman C, Choen O, Raveh L, Mazor O, Ordentlich A, Shafferman A. Polytheylene-glycol conjugated recombinant human acetylcholinesterase serves as an efficacious bioscavenger against soman intoxication. Toxicol. 2007;233(1-3):40-6. doi: 10.1016/j.tox.2006.08.036.

106. Collins $L$, Edwards $L$. Toxicity of moist snuff and impact on various stages of darkling beetles (Tenebrio molitor). Explorations. 2012;VII:23-9. Available from: https://uncw.edu/csurf/explorations/documents/explorations72012final.pdf.

107. Waqar M, Batool S. In silico analysis of binding of neurotoxic venom ligands with acetylcholinesterase for therapeutic use in treatment of Alzheimer's disease. J Theor Biol. 2015;372:107-17. doi: 10.1016/j.jtbi.2015.02.028.

108. Dutertre S, Nicke A, Tsetlin VI. Nicotinic acetylcholine receptor inhibitors derived from snake and snail venoms. Neuropharmacol. 2017;127:196-223. doi: 10.1016/j.neuropharm.2017.06.011.

109. Thany SH, Tricoire-Leignel H. Emerging pharmacological properties of cholinergic synaptic transmission: comparison between mammalian and insect synaptic and extrasynaptic nicotinic receptors. Curr Neuropharmacol. 2011;9(4):706-14. doi: 10.2174/157015911798376343.

110. Brown DA. Acetylcholine and cholinergic receptors. Brain Neurosci Adv. 2019;3(2):1-10. doi: 10.1177/2398212818820506. 